Ciudades de Lectores: Innovación docente a través de una metodología que incorpora los espacios del lector en la literatura contemporánea para la iniciación al proyecto arquitectónico

Francisco Javier Castellano Pulido, Tomás García Píriz, Ana Gallego Cuiñas, Gracia Morales Ortiz
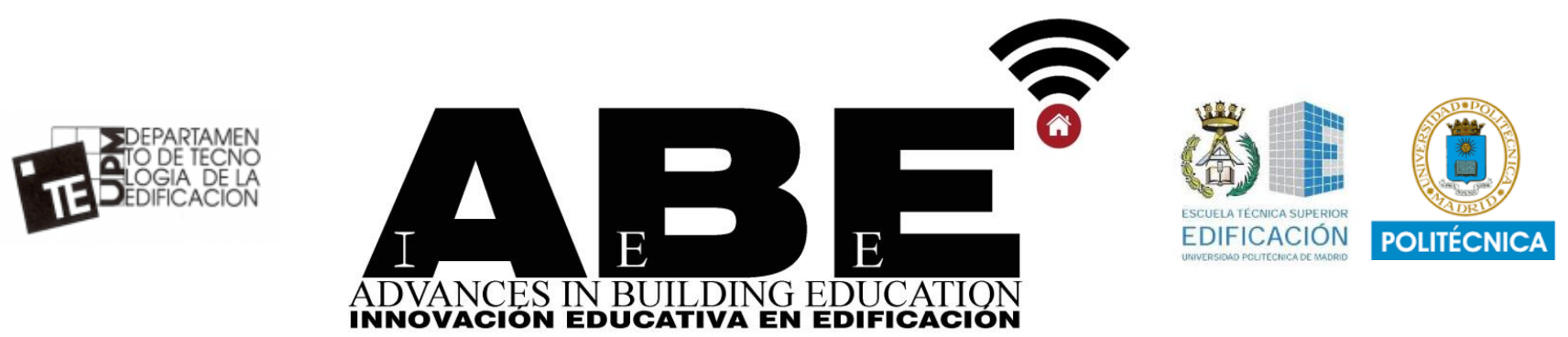

\title{
Ciudades de lectores: Innovación docente a través de una metodología que incorpora los espacios del lector en la literatura contemporánea para la iniciación al proyecto arquitectónico.
}

Cities of readers: A teaching innovation methodology that assimilates the reader spaces in the contemporary literature for the initiation to the architectural project

\footnotetext{
Francisco Javier Castellano Pulido ${ }^{{ }^{*}}$, Tomás García Píriz ${ }^{2}$, Ana Gallego Cuiñas ${ }^{3}$, Gracia Morales Ortiz ${ }^{3}$

E.T.S. de Arquitectura de Málaga. Departamento de Arte y Arquitectura. Universidad de Málaga, España

2 E.T.S. de Arquitectura de Granada. Departamento Expresión Gráfica en la Arquitectura y en la Ingeniería. Universidad de Granada, España

3 Departamento de Literatura Española. Universidad de Granada. España.

* Corresponding author email: javiercastellano@uma.es
}

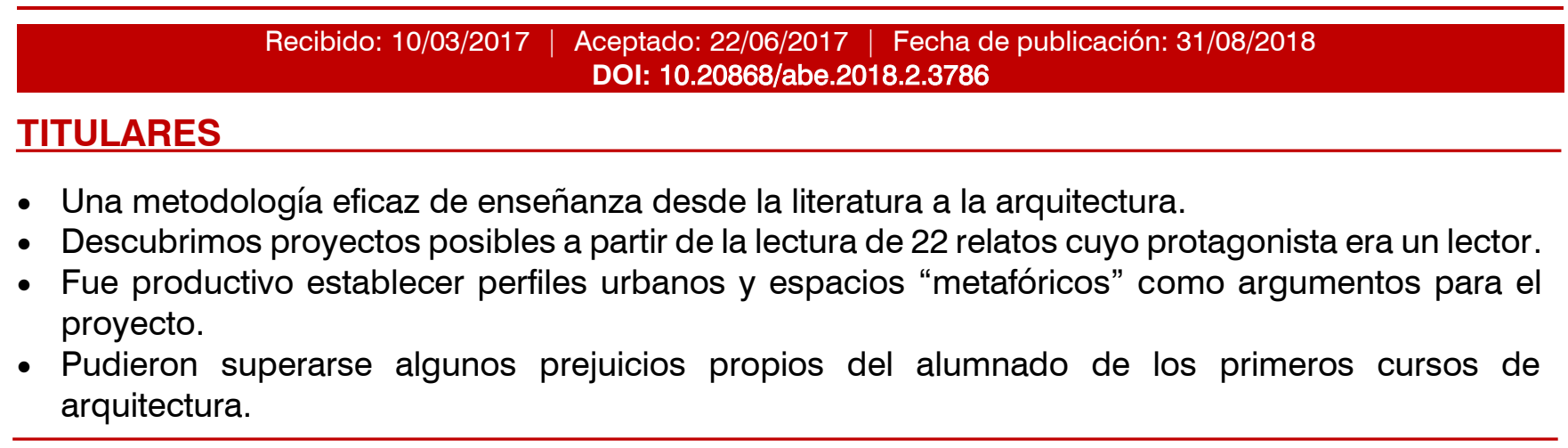

\section{HIGHLIGHTS}

- An effective teaching and learning methodology from literature to architecture.

- Many possible projects were discovered from the reading of 22 stories whose main character was a reader.

- Establishing urban profiles and "metaphorical" spaces as arguments for the project was productive.

- Some prejudices inherent to students during the first academic years of the architecture degree could be overcome. 
Ciudades de Lectores: Innovación docente a través de una metodología que incorpora los espacios del lector en la literatura contemporánea para la iniciación al proyecto arquitectónico Francisco Javier Castellano Pulido, Tomás García Píriz, Ana Gallego Cuiñas, Gracia Morales Ortiz

\section{RESUMEN}

La experiencia que aquí se presenta es resultado de la aplicación de una metodología de enseñanza y aprendizaje interdisciplinar (literatura hispanoamericana y arquitectura), transversal (combinando distintos conocimientos de áreas disímiles con elementos cotidianos y de interés social) y plural, con un anclaje real. Para ello, se ensayan operaciones de lectura, búsqueda, observación, elección, interpretación y realización de un proyecto de arquitectura a partir de la lectura de 22 relatos donde el protagonista es un lector. Desde la descripción de las cualidades espaciales del contexto de cada personaje por parte de alumnos de literatura es posible establecer una serie de perfiles urbanos que pueden ser encontrados en distintas ciudades. EI conocimiento del espacio psicológico o "metafórico" de cada lector, en cambio, permite elaborar una serie de perfiles personales y cualidades espaciales "internas" que pueden ser generadas por alumnos de arquitectura en los lugares encontrados. A través de propuestas de intervención se persigue mejorar las condiciones para la práctica de la lectura en la ciudad o se induce a vivir la experiencia psico-ambiental de cada lector en el lugar elegido. Esta estrategia docente permite superar algunos prejuicios del alumnado de los primeros cursos de arquitectura, ampliando de forma constatable el concepto previo de espacio para construir un pensamiento más rico sobre la realidad observada, una lectura personal y proyectada hacia las múltiples potencialidades del espacio urbano de la actualidad.

Palabras clave: Innovación docente; Transdisciplinar; Proyecto arquitectónico; Lectura; Arquitectura; Literatura.

\section{ABSTRACT}

The experience here presented comes from the application of an interdisciplinary teaching methodology (Spanish-American literature and architecture). It is also transversal (combining different knowledge of several areas with quotidian and social interest elements) and plural, linked to real-life. To this end, a process of searching, observing, choosing, interpreting and making an architecture project was developed from the reading of 22 stories whose main character was a reader. From the literature students' descriptions about the spatial qualities context of each character, a series of urban profiles found in different cities can be established. The knowledge of the psychological or "metaphorical" space of each reader, on the other hand, allows developing a series of personal profiles and "inner" spatial qualities that can be generated by students of architecture in the places found. Using proposals of intervention, the students will be able to improve the conditions for the practice of reading in the city or to induce the psycho-environmental experience to be lived by each reader in the chosen place. This teaching strategy allows us to overcome some of the students' inherent prejudices during their first years of the architecture degree. It expands as well the previous concept of space in order to build a richer thinking about the observed reality and a personal reading, projected towards the multiple potentialities of the current urban space.

Keywords: Teaching innovation; Transdisciplinary; Architectural Project; Reading; Architecture; Literature.

Advances in Building Education / Innovación Educativa en Edificación | ISSN: 2530-7940 | http://polired.upm.es/index.php/abe

| Cod. 0003 | Mayo - Agosto 2018 | Vol. 2. № 2 | pp. 9/31 | 
Ciudades de Lectores: Innovación docente a través de una metodología que incorpora los espacios del lector en la literatura contemporánea para la iniciación al proyecto arquitectónico

Francisco Javier Castellano Pulido, Tomás García Píriz, Ana Gallego Cuiñas, Gracia Morales Ortiz

\section{INTRODUCCIÓN}

La enseñanza de la arquitectura en el seno del Espacio Europeo de Educacion Superior (EEES) se enfrenta a la necesidad de explorar nuevas formas de aprendizaje que induzcan a entender, retener y utilizar la información para producir soluciones arquitectónicas acordes con el contexto social contemporáneo. La conocida afirmación de Le Corbusier "La clave es mirar" ha sido ampliamente utilizada para describir el modo primordial del aprendizaje de la arquitectura: "Mirar, observar, ver e imaginar" [1]. El término mirar era utilizado como sinónimo

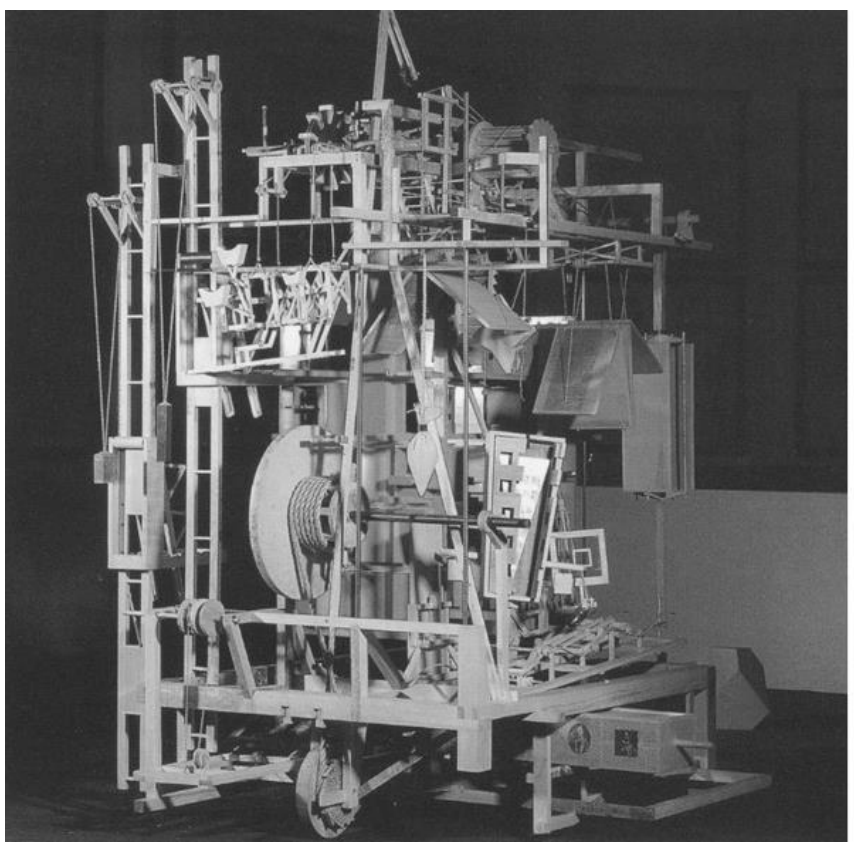

de "criticar", de establecer un juicio argumentado.

Siguiendo este razonamiento, podemos encontrar en un nivel superior, y de forma íntimamente relacionada con la mirada, a la lectura. La lectura resulta fundamental en el aprendizaje y enseñanza no solo de la literatura y la lengua escrita, sino también en la consecución de un espíritu crítico capaz de interpretar, describir y aprehender nuestra cultura y la realidad social, eminentemente textual y urbana.

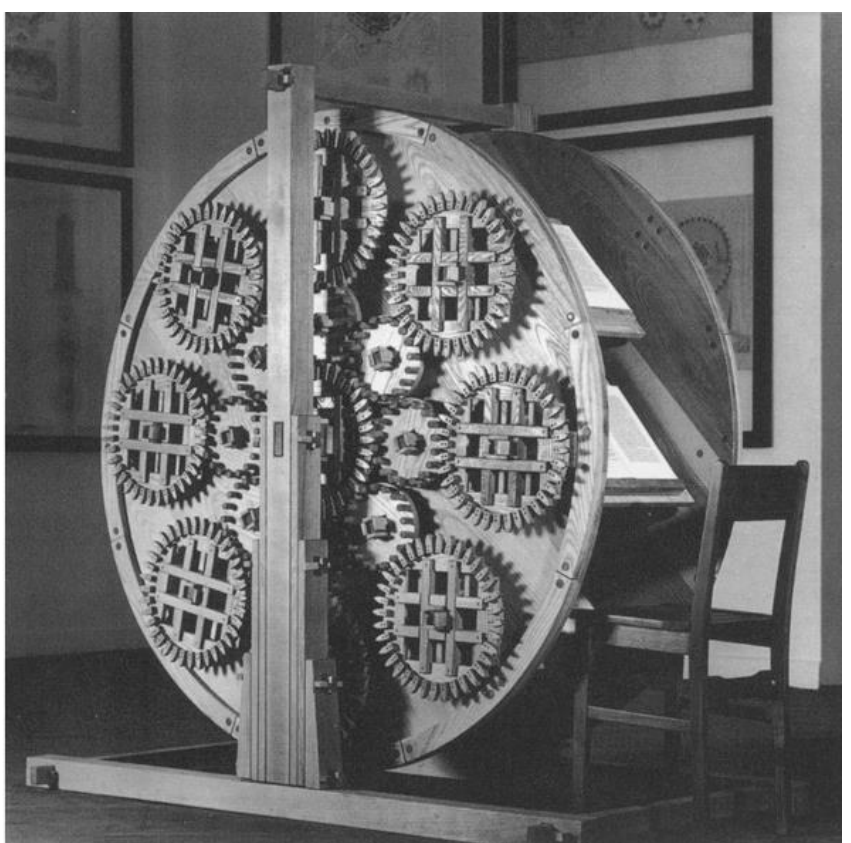

Fig. 1. Máquinas de la lectura y de la memoria. Daniel Libeskind, 1985.

La construcción del sujeto moderno se ha producido, como apunta Nora Catelli, a través de la lectura. Por esa razón, cuando se habla de la posible extinción del soporte material del libro, se hace necesario estudiar la historia de esa lectura sobre la base del encuentro entre el mundo del texto y el mundo del lector, una relación que ha cambiado considerablemente con el tiempo [2]. Las formas de lectura (usos y apropiación de los textos) han variado en el último siglo porque las condiciones y estructuras urbanas de los espacios públicos donde esta actividad se viene practicado más a menudo (bibliotecas, parques, plazas, jardines y medios

Advances in Building Education / Innovación Educativa en Edificación | ISSN: 2530-7940 | http://polired.upm.es/index.php/abe

| Cod. 0003 | Mayo - Agosto 2018 | Vol. 2. № 2 | pp. 9/31 | 


\section{Ciudades de Lectores: Innovación docente a través de una metodología que incorpora los espacios del lector en la literatura contemporánea para la iniciación al proyecto arquitectónico Francisco Javier Castellano Pulido, Tomás García Píriz, Ana Gallego Cuiñas, Gracia Morales Ortiz}

de transporte público) también se ha transformado, produciendo otro sentido y otra experiencia [3] (figura 1). Desde El Quijote, la ficción siempre se ha hecho eco de la tensión entre literatura y vida, lectura y realidad, porque el encuentro entre el lector real y el lector de ficción se produce dentro del texto, pero se extiende fuera de él: el lector real representa la escena de lectura por imitación o por sustitución. Por esta razón resulta imprescindible contestar también a otra cuestión crucial "¿cómo se lee en la ficción?", pues la lectura se convierte en una forma de conocer la realidad que, por imitación o rechazo, condiciona nuestra práctica lectora en el espacio privado y público de la ciudad que nos rodea.

A esta cuestión responde el Proyecto de Innovación Docente Ciudad de Lectores, en el que los alumnos han prestado atención a las figuras de lectura en la ficción narrativa del siglo XX y lo han relacionado con espacios de la ciudad de Granada y Málaga. Porque si la realidad contemporánea es marcadamente urbana, y más aún la del estudiante universitario, el estudio de los modos de escribir, de hacer visible lo que se ha leído, puede llevar a desentrañar el efecto de las prácticas de la lectura en la literatura y en la ciudad. Esta experiencia persigue el aprendizaje de otras formas de leer los textos literarios y otras formas de "leer la ciudad". Y no solo desde el aula universitaria, sino también desde la intervención en la propia ciudad, en este caso, Granada y Málaga.

La estrategia docente que aquí se describe parte de la premisa de que es posible iniciar el aprendizaje de la arquitectura desde una perspectiva atenta a la complejidad de los hábitos del comportamiento humano si se introduce, desde los primeros cursos, un cierto paralelismo e intercambio con los contenidos espaciales de la construcción del texto literario.
La participación de profesores y alumnos universitarios de literatura, lengua y arquitectura en un mismo proyecto de innovación educativa ofrece múltiples posibilidades, sobre todo el lo que se refiere al intercambio de léxico y "constructos" conceptuales que pueden ser transferidos al espacio físico por parte del arquitecto. En este caso, elegimos 22 textos de la literatura contemporánea cuyo factor en común es que en todos ellos el protagonista es un lector. Esta elección obedece a la necesidad de probar no tanto los beneficios educativos que supone la posible traducción del contenido de un texto de ficción a un proyecto de arquitectura como, sobre todo, a las consecuencias derivadas de la incorporación de una actividad como la lectura como programa de necesidades arquitectónico. Centrar la atención en las múltiples formas y lugares en las que esta puede desarrollarse en la actualidad facilita la superación de ciertos prejuicios vinculados a la común asociación uso-actividad. Es decir, responder a la lectura como función principal del proyecto permite soslayar con más facilidad la traducción directa de una necesidad a un tipo de habitación concreto, tal y como suele suceder con la incorporación de los programas residenciales cuando se plantean en el primer curso de Proyectos Arquitectónicos (véase el libro de Perec La vida: Instrucciones de uso [4]). Debilitar estos prejuicios derivados de experiencias pre-universitarias resulta fundamental en la adquisición de un verdadero juicio crítico que ayude al alumno a reflexionar sobre cómo la arquitectura puede responder a los nuevos hábitos sociales.

Situar al lector como personaje central en esta experiencia induce, por otra parte, a indagar en la figura del "usuario" de un modo rico y complejo desde el punto de vista psicológico. De esta forma, el destino del ejercicio final no deja de ser la simulación de un proyecto 
Ciudades de Lectores: Innovación docente a través de una metodología que incorpora los espacios del lector en la literatura contemporánea para la iniciación al proyecto arquitectónico

Francisco Javier Castellano Pulido, Tomás García Píriz, Ana Gallego Cuiñas, Gracia Morales Ortiz

arquitectónico para un usuario ficticio que puede ser conocido a través de la literatura.

Para la realización de esta simulación se han recorrido dos caminos: el primero de ellos se ha desarrollado en la ciudad de Granada y el segundo, entre Granada y Málaga. En ambos casos se ha seguido un esquema de intercambio de información parecido, pero con ciertas diferencias (figura 2).

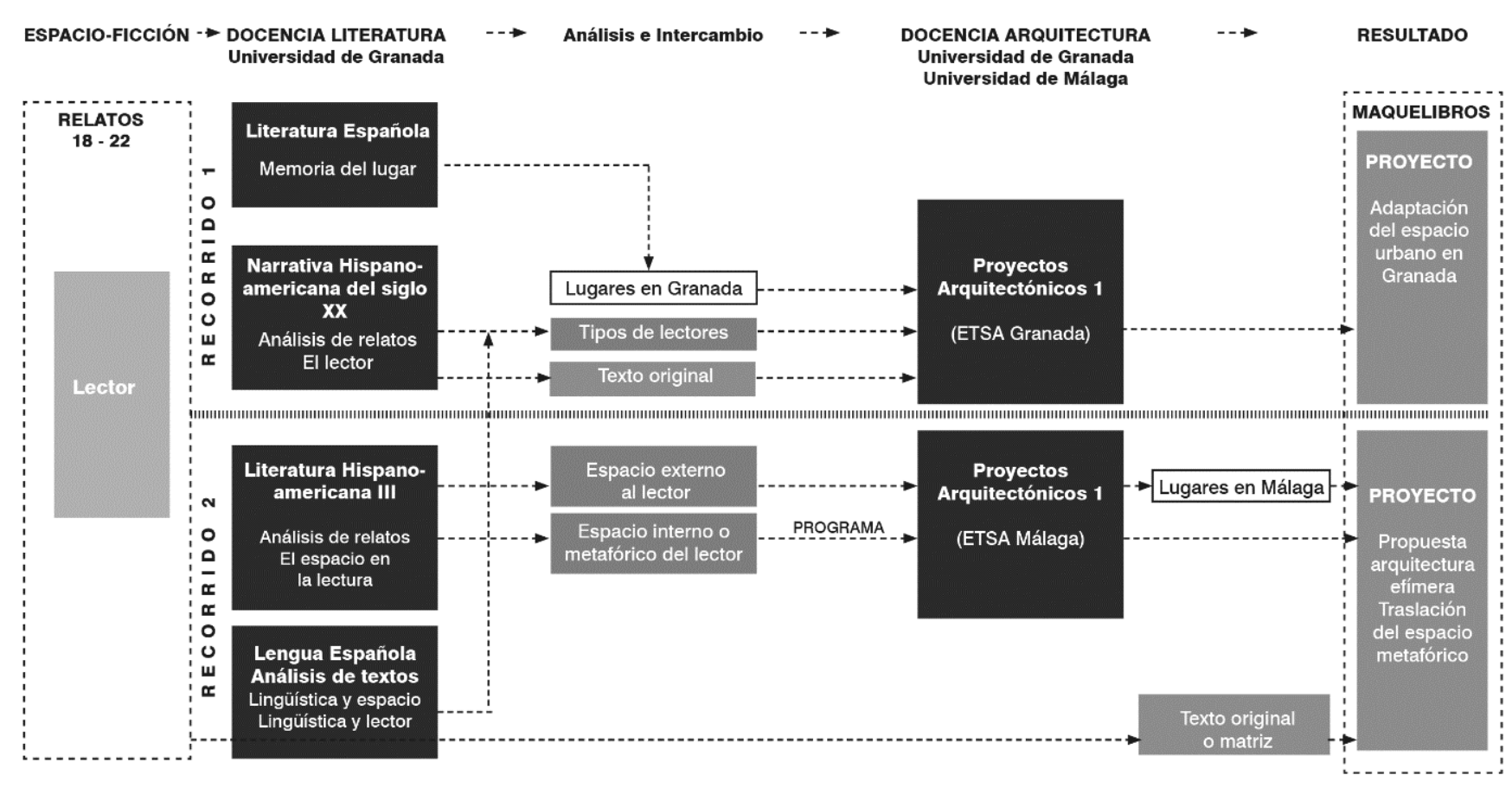

Fig. 2. Esquema de transferencia literatura-arquitectura

\subsection{Primer recorrido: Del relato a la Ciudad de Granada. Los distintos tipos de lector}

La primera fase del trabajo de cooperación interdisciplinar llevado a cabo por los alumnos de la asignatura Narrativa Hispanoamericana del siglo XX de la Universidad de Granada (UGR) consistió en reflexionar acerca del acto de lectura en la ficción y la relación del lector con la lectura en 18-22 textos representativos de la narrativa hispanoamericana del siglo XX (figura 3). Se formaron grupos de 2 a 3 alumnos, eligiendo un texto de ficción del dossier facilitado por la profesora de Narrativa para poder analizarlo y exponer sus conclusiones por escrito con un máximo de 2 páginas. El resultado obtenido fue una suerte de "definición" del tipo de lector y del acto de lectura que se representa en cada texto escogido (tabla 1), en función de los siguientes interrogantes:

- Quién: sexo, edad, clase social, nacionalidad, profesión, personalidad)

- Dónde: espacios privados como la casa, el dormitorio o el jardín; espacios de concurrencia pública cerrados como cafés, bibliotecas, salas de lectura o espacios urbanos abiertos como parques, plazas, jardines, medios de transporte público y privado; país, provincia; elemento de apoyo: silla, sofá, banco, suelo... 
Ciudades de Lectores: Innovación docente a través de una metodología que incorpora los espacios del lector en la literatura contemporánea para la iniciación al proyecto arquitectónico

Francisco Javier Castellano Pulido, Tomás García Píriz, Ana Gallego Cuiñas, Gracia Morales Ortiz

- Cuándo: de día, de noche, hora, estación, clima...

- Cómo: sentado, de pie, momento emocional, haciendo otra actividad...

- Qué: tipo de lectura

- Para qué: relación del lector con la lectura, conciencia de la elección y función de la lectura, cómo afecta la lectura al lector, es decir, ¿hay algún tipo de transformación en el lector después de la lectura?

El resultado obtenido consistió en la obtención de una serie de textos descriptivos por cada uno de los textos originales que incluían la denominación del lector y su justificación:

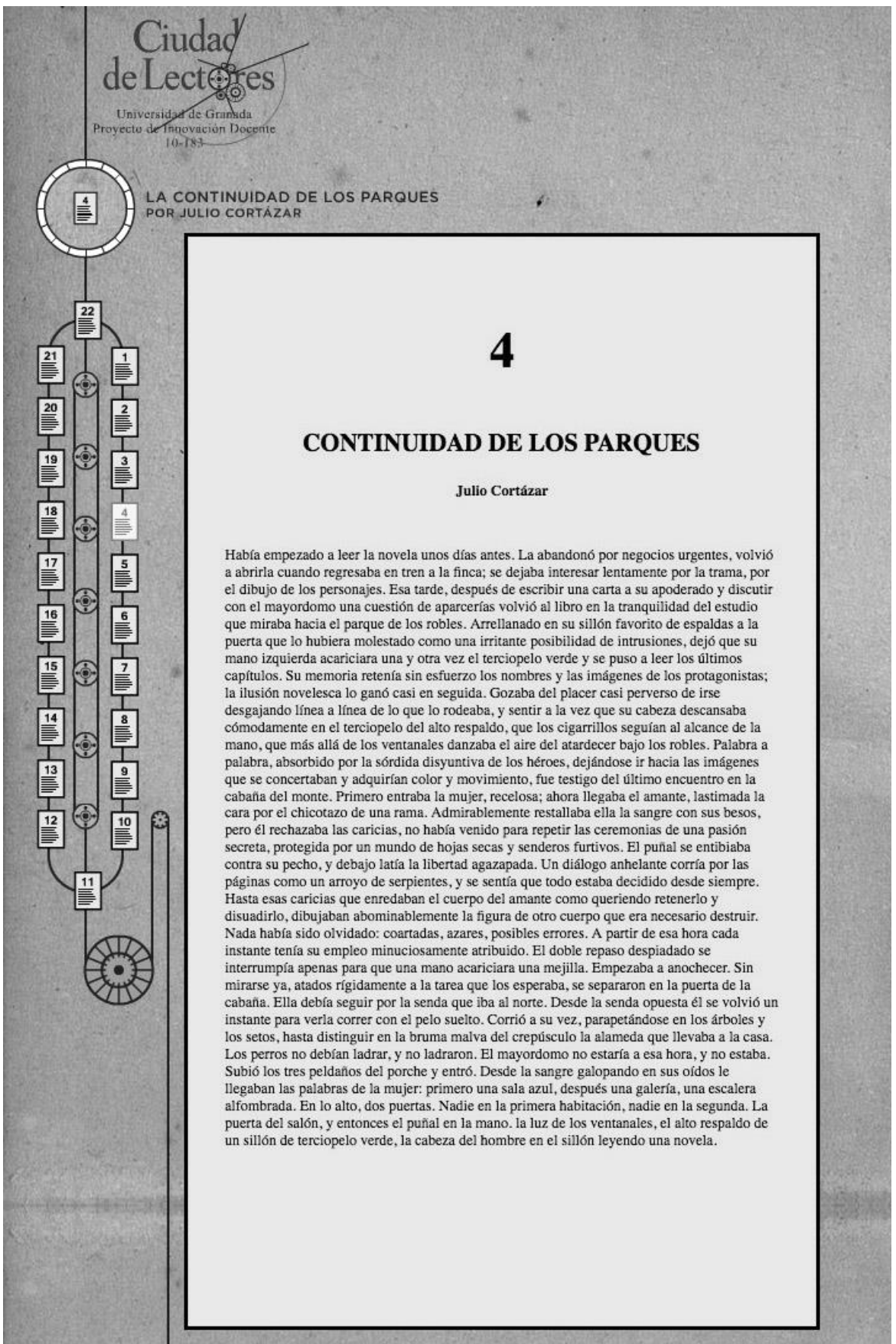

Fig. 3. Ejemplo de relato entregado a los alumnos de

Narrativa Hispanoamericana del siglo XX y de Literatura Hispanoamericana III

Advances in Building Education / Innovación Educativa en Edificación ｜ ISSN: 2530-7940 http://polired.upm.es/index.php/abe 


\section{Ciudades de Lectores: Innovación docente a través de una metodología que incorpora los espacios del lector en la literatura contemporánea para la iniciación al proyecto arquitectónico Francisco Javier Castellano Pulido, Tomás García Píriz, Ana Gallego Cuiñas, Gracia Morales Ortiz}

\section{Tipo de lector}

El lector-escalera (el lector que pasa de un estadio a otro

El lector encapsulado (como los lectores que leen en el baño)

El lector-río (el lector que zigzaguea, que se esconde y aparece)

El lector encantado (relacionado con el misterio y la magia)

El lector atrapado

El lector aventurero (muy relacionado con el escritor y la crítica literaria)

El lector-aleph

El lector-espejo

El lector fragmentado

El lector conquistador (el que lee para seducir)

El lector-bandoleresco (ladrón, falsificador, a los "Arlt")

El lector maldito

El lector ecuménico

El lector reflexivo

El lector diamante (como Coleridge, sacando provecho de todo lo que lee).

El lector posimposible

El lector investigador

El lector en Si Menor (como la sonata de Liszt)

\section{Lectura}

"Amor y pedagogía" de Miguel de Unamuno

"Amuleto" de Roberto Bolaño

"Apuntes para una teoría del lector" de Rodrigo Fresán

"Aura" de Carlos Fuentes

"Continuidad de los parques" de Julio Cortázar

"Una aventura literaria" de Roberto Bolaño

"El último lector" de Ricardo Piglia

"Maneras de estar preso" de Julio Cortázar

"El arte de la pérdida" de Cristina Peri Rossi

"El hombre que hablaba de Octavia de Cádiz" de A. B. Echenique

"El juguete rabioso" de Roberto Arlt.

"El libro en blanco" de Julio Ramón Ribeyro.

"La biblioteca de Babel" de Jorge Luis Borges

"La hija del filósofo" de Elena Poniatowska

"La lengua" de Patricia Ratto

"Tlön, Uqbar, Orbis Tertius" de Jorge Luis Borges.

"Un pez en el hielo" de Ricardo Piglia.

"Vals de Mefisto" de Sergio Pitol

Tabla 1. Tipos de lectores obtenidos por cada relato

\subsubsection{Espacios urbanos para lectores ficticios}

Los alumnos de Literatura Española reflexionaron posteriormente sobre la significación del espacio en el texto y cómo la lectura determina el modo en que se lee, a través de la búsqueda de espacios urbanos reales propicios para la lectura $y$, por tanto, aptos para diferentes tipos de lectores. Para ello, buscaron lugares en la ciudad de Granada propicios para cada tipo de lector, justificando su elección, y realizando un trabajo de representación plástica (fotografía, vídeo, audio o ficción escrita) acerca del lector y el lugar escogido.

\subsubsection{La lectura como actividad transformadora del espacio urbano: el espacio urbano del lector}

Los modos de entender y habitar la ciudad influyen directamente en el lector, de forma que este puede ser al mismo tiempo agente transformador y vehículo de transmisión entre tiempos y espacios diferentes. La lectura es, por otra parte, una forma de sociabilidad, lo que permite entender hasta qué punto el cambiante contexto urbano afecta a su modo de relacionarse con el texto. Para comprender esta relación lectura-espacio urbano, cada alumno de Proyectos Arquitectónicos 1 de la Universidad de Granada recibió las definiciones de los tipos de lectores realizados por los alumnos de Narrativa Hispanoamericana junto a la selección de espacios realizados por los alumnos de Literatura Española. Este material, proporcionado al mismo tiempo que el texto original de cada relato, adquirió forma de "programa de necesidades" a satisfacer por parte del proyecto de arquitectura. El ejercicio propuesto consistió en la realización de una propuesta de mejora del espacio urbano para la lectura en función de cada tipo de lector y cada espacio elegido. Para ello, los alumnos de arquitectura analizaron las condiciones urbanísticas, geográficas y ambientales (condiciones lumínicas, acústicas, higrométricas...) del lugar, utilizando la intervención arquitectónica como herramienta prospectiva de inducción a la lectura. Finalmente, los alumnos entregaron un proyecto de intervención arquitectónica en el lugar escogido de la ciudad de Granada capaz de adaptarlo a la lectura en función del tipo de lector (figura 4). La cuestión principal que subyacía a este ejercicio era: ¿Hasta qué punto los lectores pueden transformar un lugar? 
Ciudades de Lectores: Innovación docente a través de una metodología que incorpora los espacios del lector en la literatura contemporánea para la iniciación al proyecto arquitectónico Francisco Javier Castellano Pulido, Tomás García Píriz, Ana Gallego Cuiñas, Gracia Morales Ortiz
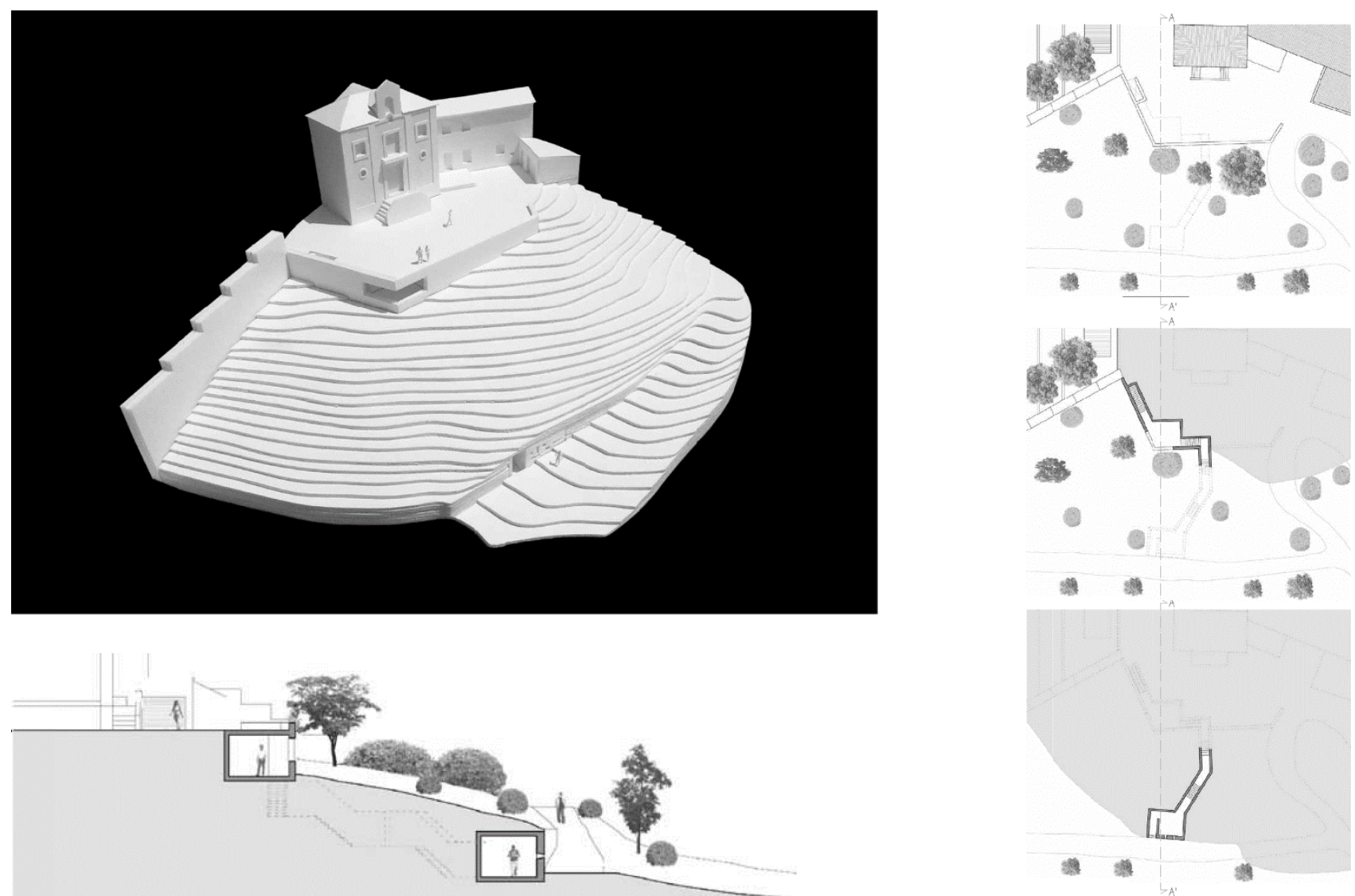

Fig. 4. Ejemplo de propuesta del recorrido 1 en la ciudad de Granada. (Alumno: Sastre, A.)

1.2. Segundo recorrido: del relato a la Ciudad de Málaga. La lectura como metáfora espacial.

La presencia de un lector en cada uno de los textos de ficción permite distinguir entre dos "espacialidades" literarias, aquella relacionada con las condiciones del contexto en el que se desarrolla la acción de leer (denominada por nosotros "espacio externo al lector" y, la más compleja, la sensación espacial que el texto provoca en el lector (denominada por nosotros como "espacio interno" o "espacio metafórico"). Según esta lógica, un relato puede provocar sensación de ahogo o claustrofobia en un lector que se encuentra en un espacio amplio y transitado como puede ser un aeropuerto $\mathrm{o}$, en sentido contrario, puede ayudar a generar una cierta sensación de intimidad y recogimiento en un espacio público muy expuesto a la mirada de transeúntes. Dicho de otro modo, un tipo de lectura puede transformar metafóricamente el espacio del lector, de forma que el lector puede encontrarse desorientado y a oscuras en un espacio luminoso, encerrado o encarcelado en un espacio al aire libre y eso es lo que sucede en los relatos elegidos; la lectura cambia la sensación espacial del lector esté donde esté.

A partir de los distintos textos de partida (figura 5), los alumnos de la asignatura Literatura Hispanoamericana III realizaron un análisis del espacio en el que se encuentra cada personaje del texto de ficción en el momento de la lectura, trasladando esta información a la clase de Proyectos Arquitectónicos 1 de la Escuela Técnica Superior de Arquitectura (ETSA) de Málaga. 
Ciudades de Lectores: Innovación docente a través de una metodología que incorpora los espacios del lector en la literatura contemporánea para la iniciación al proyecto arquitectónico Francisco Javier Castellano Pulido, Tomás García Píriz, Ana Gallego Cuiñas, Gracia Morales Ortiz

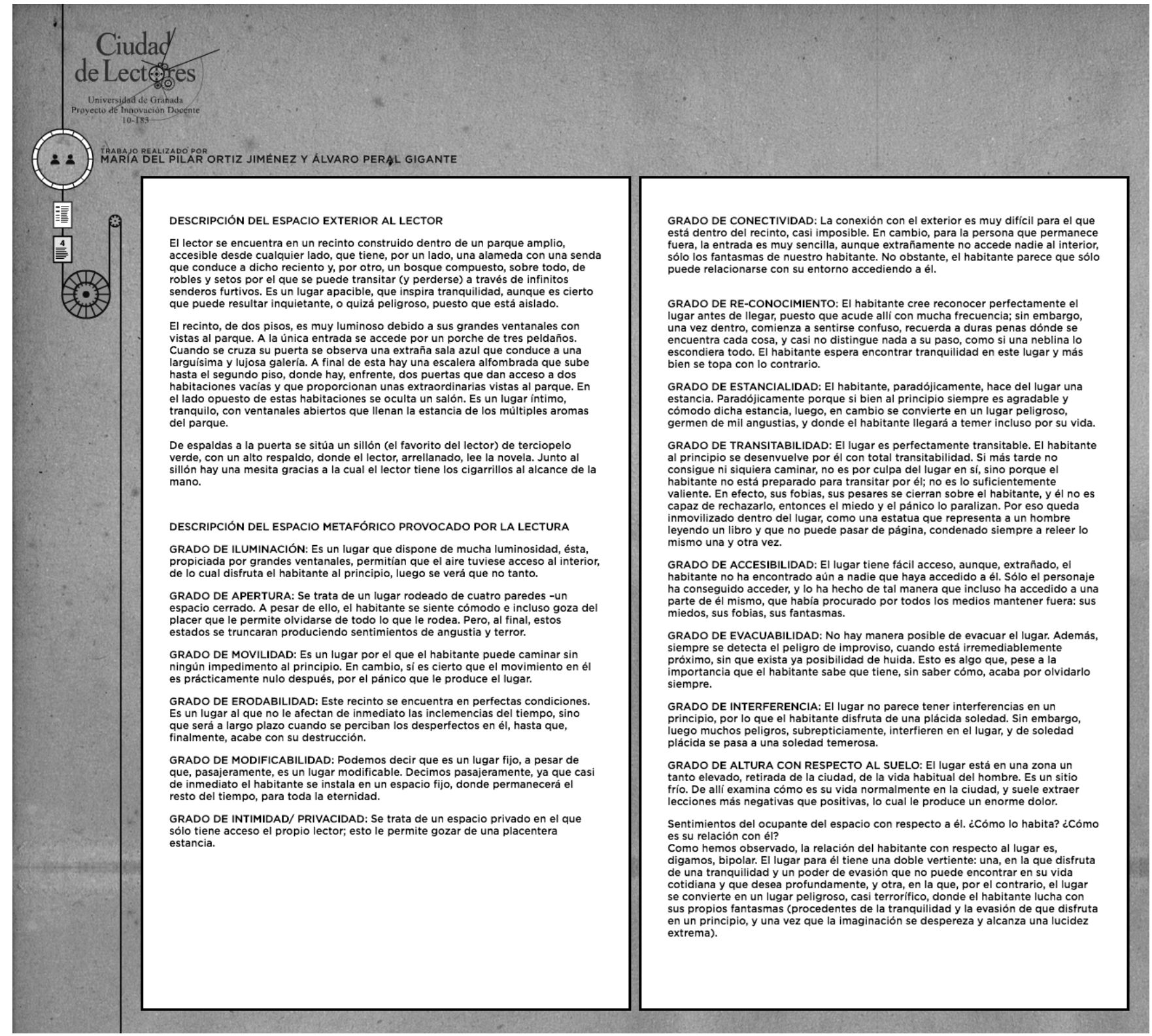

Fig. 5. Ejemplo de fichas descriptivas transferidas desde los alumnos de Literatura Hispanoamericana III a Proyectos arquitectónicos 1 
Ciudades de Lectores: Innovación docente a través de una metodología que incorpora los espacios del lector en la literatura contemporánea para la iniciación al proyecto arquitectónico Francisco Javier Castellano Pulido, Tomás García Píriz, Ana Gallego Cuiñas, Gracia Morales Ortiz

\subsubsection{La "lectura" del espacio metafórico}

Esta fase requiere de un pensamiento más complejo. Se trata de un ejercicio más abstracto e interesante para la docencia, pues permite desarrollar un pensamiento crítico y fuertemente creativo. La lectura puede ser un modo de transportar al lector a otro sitio. De cambiar su ubicación: ¿cómo es el lugar al que el lector de cada relato se traslada cuando se concentra en su texto? No se trata de un lugar geográfico concreto sino de un lugar simbólico que podemos definir como "espacio metafórico". Se formularon tres ejemplos:
1. Hay personas que buscan libros que les hagan sentir cómodos en un lugar reconocible, lectores que buscan sentirse como en su casa.

2. Hay quienes desean, por el contrario, que la lectura les lleve a un lugar desconocido, inseguro, tal vez un sitio en el que perderse: la lectura sería como un laberinto donde nos dejamos enredar.

3. Hay lectores que buscan que los libros les ayuden a conocer el mundo, a tener una mirada panorámica sobre él: la lectura sería como una torre a la que subirnos y desde la que dominar la realidad.
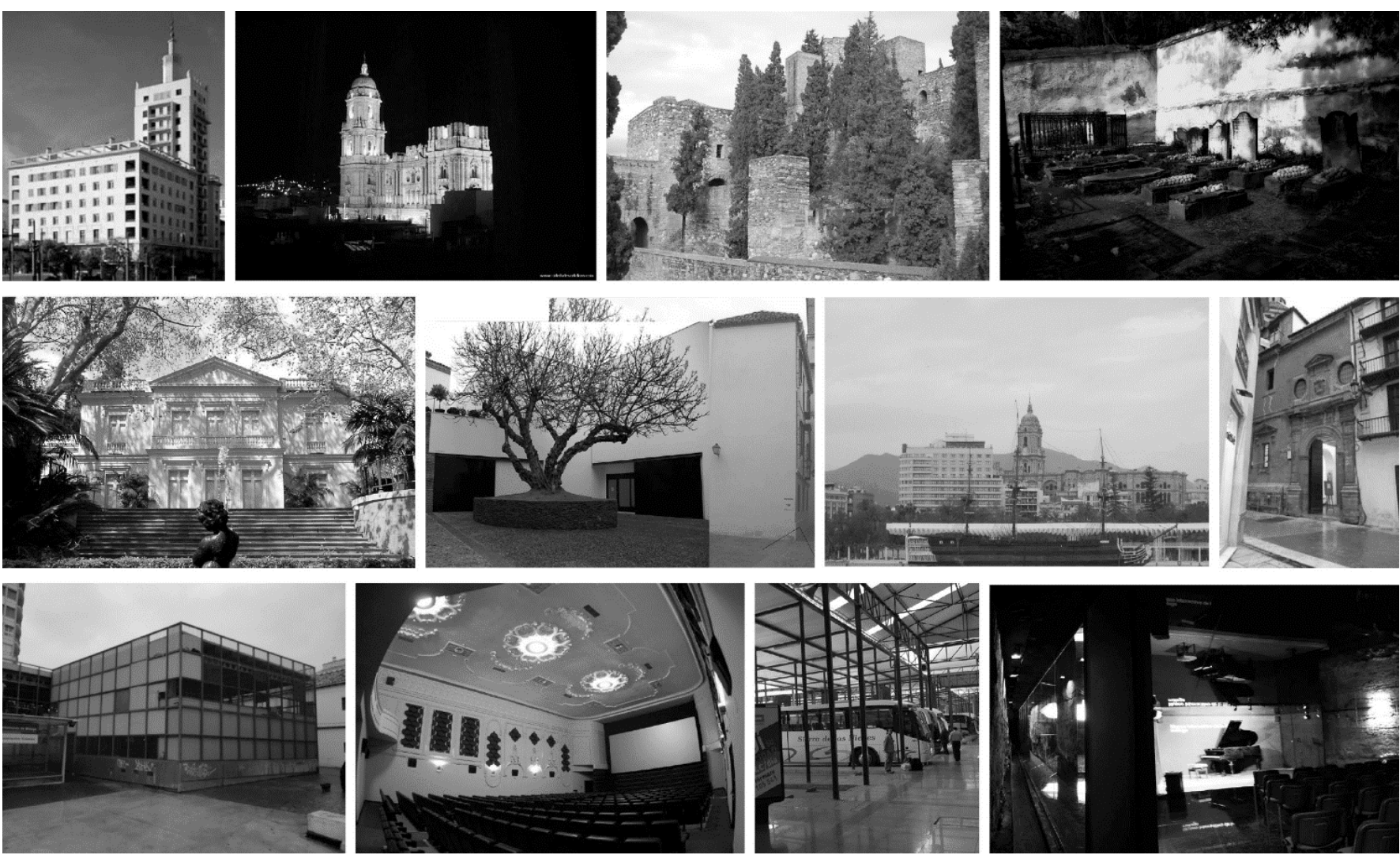

Fig. 6. Ejemplo de selección de lugares coincidentes con el relato en la ciudad de Málaga 


\section{Ciudades de Lectores: Innovación docente a través de una metodología que incorpora los espacios del lector en la literatura contemporánea para la iniciación al proyecto arquitectónico Francisco Javier Castellano Pulido, Tomás García Píriz, Ana Gallego Cuiñas, Gracia Morales Ortiz}

El ejercicio por parte de los alumnos de literatura consistió en describir las características de los distintos lugares a los que son trasladados los lectores según ciertas cualidades espaciales en distintas intensidades:

- Grado de iluminación

- Grado de apertura

- Grado de movilidad

- Grado de erodabilidad

- Grado de modificabilidad

- Grado de intimidad o privacidad

- Grado de conectividad

- Grado de re-conocimiento

- Grado de estancialidad

- Grado de transitabilidad

- Grado de accesibilidad

- Grado de evacuabilidad

- Grado de interferencia

- Grado de elevación respecto al suelo

El resultado obtenido se presentó en forma de fichas descriptivas que contenían las condiciones ambientales del lugar simbólico en que transcurre el acto de lectura en cada texto (figura 6).

\subsubsection{Espacios urbanos para lectores} ficticios: aprender a "ver el lugar"

A diferencia del recorrido primero realizado en la ciudad de Granada, los alumnos de la asignatura Proyectos Arquitectónicos 1 de la ETSA de Málaga desconocían el título y el contenido de los textos originales. Recibieron en primer lugar, y de forma aleatoria, las fichas descriptivas de las cualidades espaciales obtenidas por los alumnos de literatura. Su primera labor consistía en buscar lugares en
Málaga que pudieran responder a las características descritas en cada ficha. Este trabajo, realizado de forma individual, permitió, tras la exposición y la justificación de los lugares elegidos, seleccionar los 18 lugares más apropiados para intervenir.

\subsubsection{Análisis de las cualidades espaciales identificadas: "Leer el lugar"}

El trabajo siguiente se desarrolló en grupos de 3 y permitió profundizar en el análisis de cada ámbito elegido de forma previa a la intervención. Se estudió en profundidad el lugar, sus dimensiones y cualidades espaciales, buscando información para expresarla mediante el dibujo, aprendiendo de su evolución en el tiempo, de las actividades que se desarrollan en la actualidad y de las que se han desarrollado a lo largo del tiempo, de la memoria colectiva, de los elementos preexistentes, de los eventos y de las expectativas o proyecciones.

El trabajo en grupo y el trabajo individual permitieron ampliar, mediante el dibujo, el conocimiento de los lugares elegidos, midiendo todo lo que era considerado importante en relación a las cualidades del "espacio externo" del lector.

\subsubsection{La construcción del espacio metafórico de la lectura en el espacio físico: aprender a "escribir el lugar"}

Las fichas de cualidades espaciales del "espacio metafórico" realizadas por los alumnos de literatura fueron trasladadas a cada alumno de arquitectura atendiendo a la correspondencia con el texto original o "texto matriz" de donde procedían. Sobre cada lugar elegido en la ciudad de Málaga, cada alumno de Proyectos Arquitectónicos 1 debía realizar un proyecto de arquitectura efímera capaz de provocar una experiencia similar a la experimentada por el lector en del relato. Es decir, debían realizar una 


\section{Ciudades de Lectores: Innovación docente a través de una metodología que incorpora los espacios del lector en la literatura contemporánea para la iniciación al proyecto arquitectónico Francisco Javier Castellano Pulido, Tomás García Píriz, Ana Gallego Cuiñas, Gracia Morales Ortiz}

propuesta de modificación del espacio preexistente que permitiera inducir a cualquier visitante a vivir el "espacio interno" o metafórico que habían identificado los alumnos de literatura en cada texto literario. De este modo, el programa de necesidades arquitectónico que recibió cada alumno, centrado en esta experiencia psico-ambiental, podía superar las condiciones de habitabilidad convencionales a las que suele responder el trabajo del arquitecto, introduciendo otro tipo de "necesidades" de orden cultural. Esta estrategia permite mejorar, de un modo claro, la capacidad de los alumnos de los primeros cursos de arquitectura para abordar cuestiones de orden socio-cultural y antropológico, fundamentales en la comprensión de la arquitectura y en la construcción de la ciudad desde sus orígenes [5].

Los "texto matriz", es decir los relatos originales, fueron entregados en esta última fase a los alumnos de arquitectura para permitir una segunda interpretación de la información recibida. Esta decisión puede ser comparada, en el ejercicio profesional, a la posibilidad de conocer las necesidades de los usuarios que van habitar un proyecto de arquitectura, más allá de los programas de necesidades que suelen redactarse en los concursos de licitación o en proyectos de impacto social.

\subsubsection{Los maque-libros}

La tradicional presentación del proyecto arquitectónico en formatos DIN-A1 con la documentación gráfica de cada propuesta se complementó con la realización de una suerte de libro-maqueta que contenía una recopilación y descripción de todo el proceso de trabajo, incluyendo los pensamientos y dibujos de cada etapa de desarrollo del proyecto, desde la recepción de textos y el análisis de los lugares hasta las propuestas de intervención.
Como sugiere su nombre (acuñado por los profesores responsables de este proyecto de innovación docente), cada maque-libro podía ser excavado, horadado, plegado o transformado de la mejor forma para expresar el proyecto de arquitectura. Algo similar a lo que Ólafur Elíasson propone en el interesante libro Your house [6].

Por esa razón, algunos de los maque-libros incluían lentes o "mirillas", de modo que era posible apreciar en su interior un espacio iluminado a través de las perforaciones realizadas en cada hoja. En cualquier caso, la técnica, materiales y el sistema de construcción de cada libro-maqueta debía obedecer al concepto principal propuesto por cada proyecto de arquitectura, es decir, debía responder a la representación espacial de cada lectura como lugar simbólico (figuras 7 y 8).

Algunos trabajos consiguieron alcanzar un grado de profundidad excepcional en cuanto a la vinculación conceptual entre los textos, las propuestas y los libros-maqueta. La introducción de las lecturas superpuestas, las capas del tiempo y la consideración de la memoria colectiva en la ciudad fueron transferidas a la misma forma y la técnica constructiva de los libros. Algo similar pudo verse en aquellos proyectos que interpretaron "meta-relatos" como Continuidad de los parques, de Julio Cortázar es decir, la posibilidad de transferir la idea de un relato dentro de otro no solo a la propuesta de arquitectura efímera sino también al maque-libro, mostrando el proyecto como un documento encuadernado que se sitúa dentro de otro libro mayor que a su vez describe todo el proceso de trabajo, desde la lectura inicial hasta el dibujo de los primeros esbozos de la propuesta (figuras 9 y 10). 
Ciudades de Lectores: Innovación docente a través de una metodología que incorpora los espacios del lector en la literatura contemporánea para la iniciación al proyecto arquitectónico Francisco Javier Castellano Pulido, Tomás García Píriz, Ana Gallego Cuiñas, Gracia Morales Ortiz
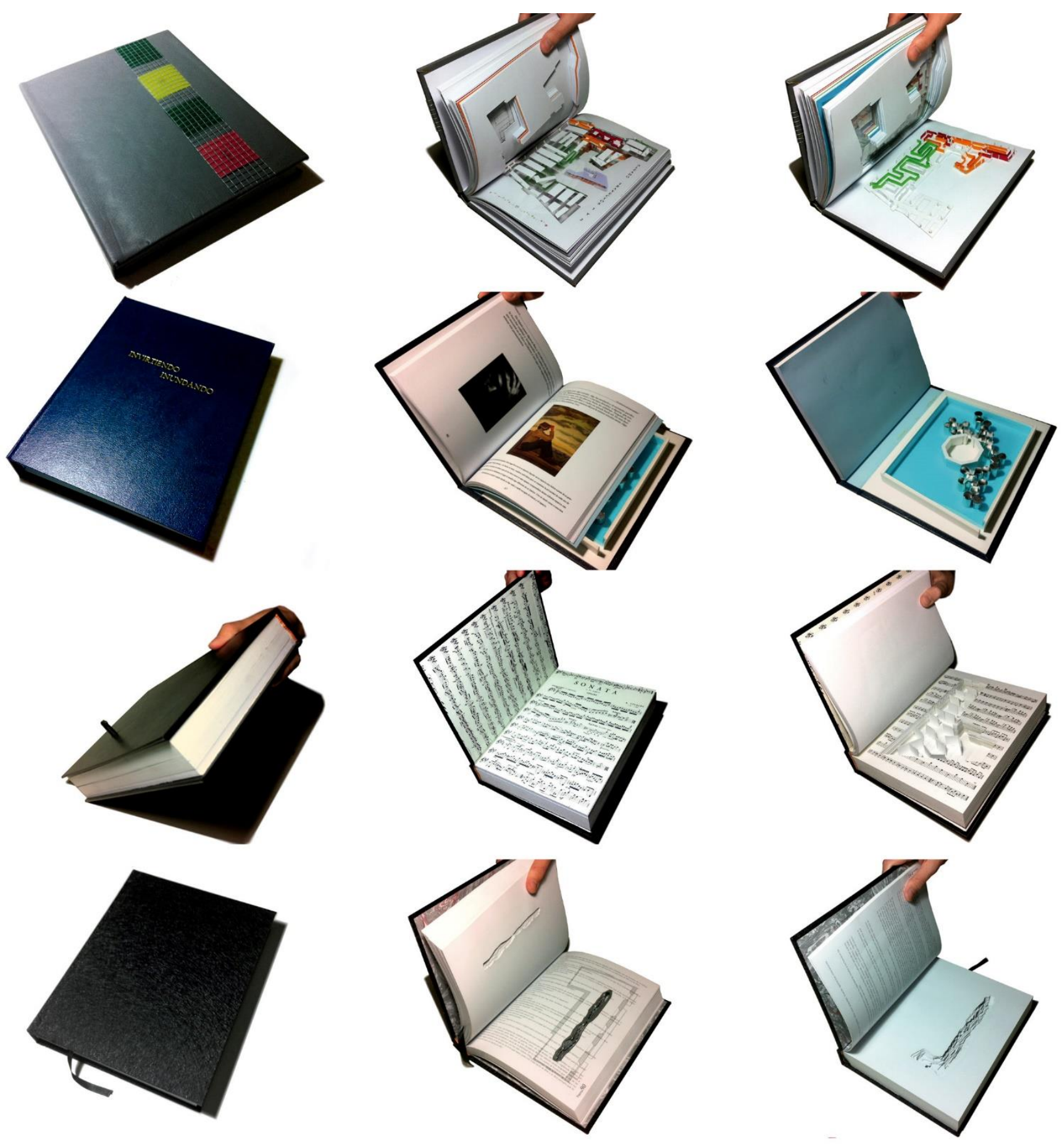

Fig. 7. Ejemplo de maque-libros excavados 
Ciudades de Lectores: Innovación docente a través de una metodología que incorpora los espacios del lector en la literatura contemporánea para la iniciación al proyecto arquitectónico Francisco Javier Castellano Pulido, Tomás García Píriz, Ana Gallego Cuiñas, Gracia Morales Ortiz
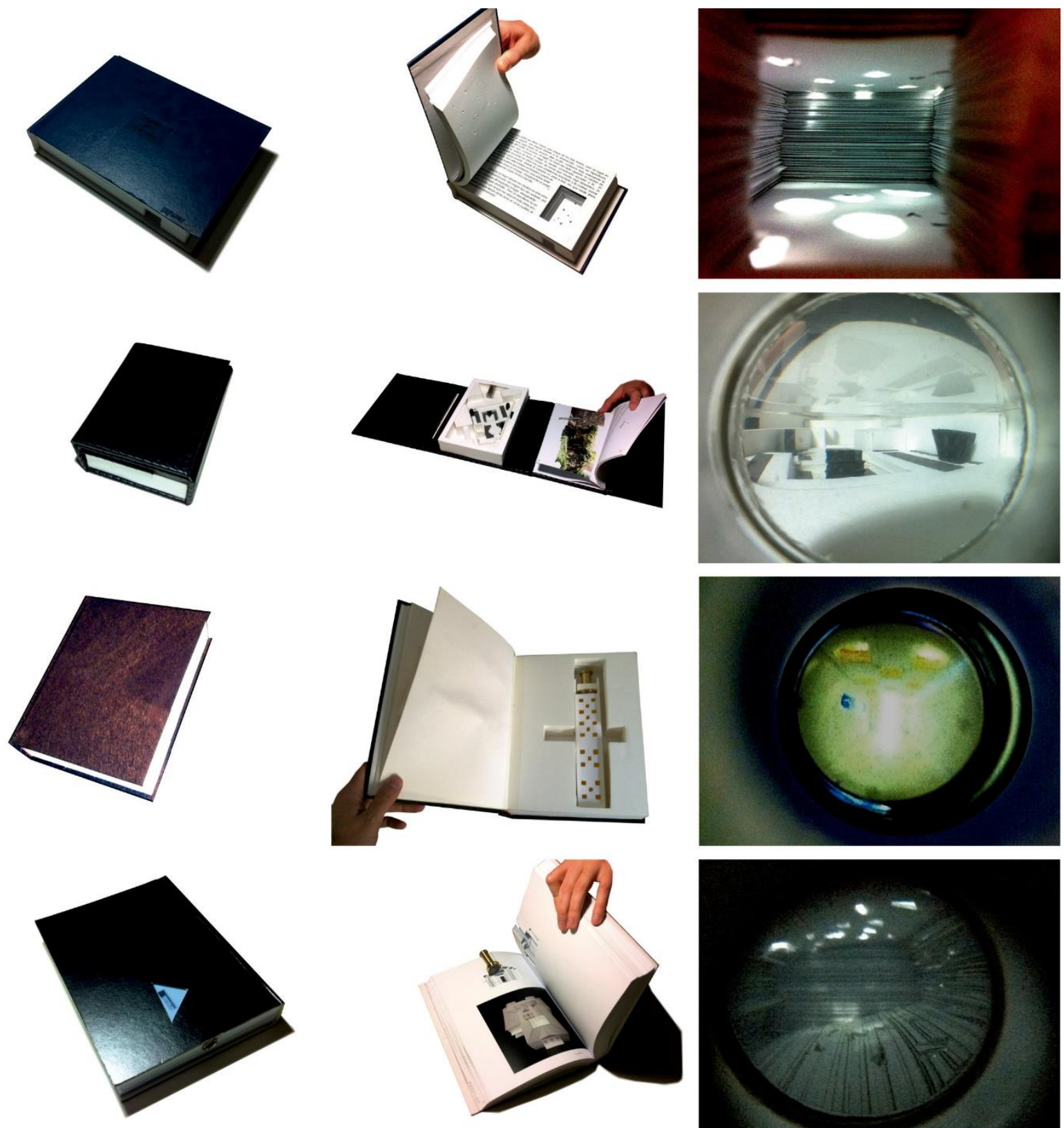

Fig. 8. Ejemplo de maque-libros con lente para observación de su interior 
Ciudades de Lectores: Innovación docente a través de una metodología que incorpora los espacios del lector en la literatura contemporánea para la iniciación al proyecto arquitectónico Francisco Javier Castellano Pulido, Tomás García Píriz, Ana Gallego Cuiñas, Gracia Morales Ortiz

\section{MATERIALES}

\subsection{Materiales y técnicas de trabajo}

La necesaria integración de las TICs en la enseñanza universitaria de la arquitectura no solo necesita producirse a través del empleo en el aula de medios informáticos o de tablones de docencia, sino también con el uso de aplicaciones y actividades en entornos digitales que claramente potencien la participación del alumno [7]. Con el sistema propuesto es posible atenuar el escaso tiempo del que dispone el profesor para exponer los contenidos y desarrollar las actividades programadas en las asignaturas de una manera atractiva y creativa. De otra parte, el alumnado también se enfrenta con nuevos desafíos en el EEES que suponen notables cambios en sus hábitos de aprendizaje y comportamiento en clase, pasando a adquirir mayor autonomía y trabajando de forma cooperativa.

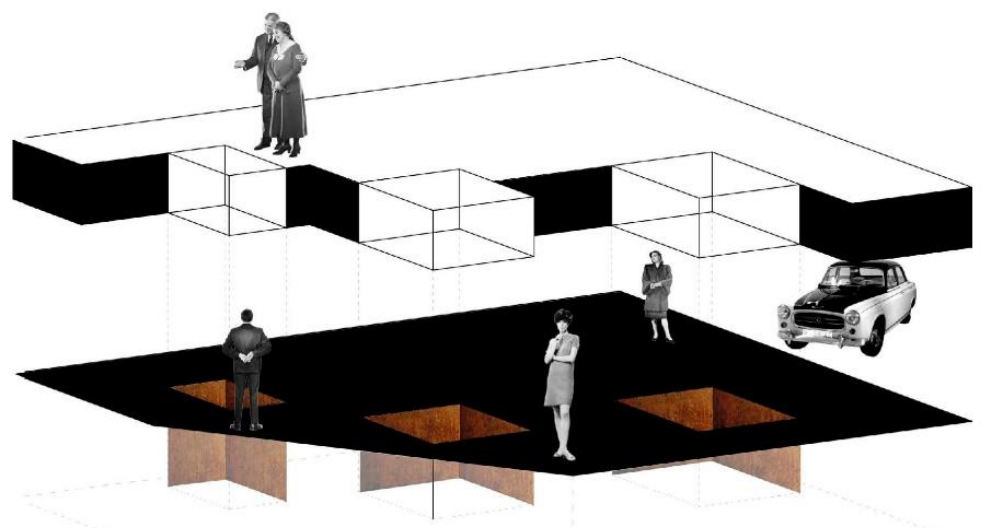

MATERIALES

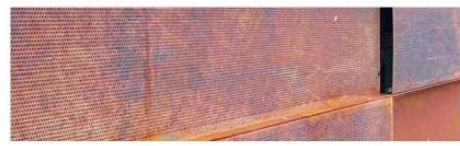

Lúminas perforadas de Acero cotén.

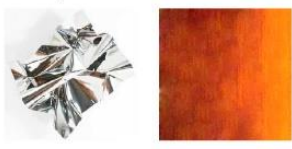

Acero B1, 2010. Lámina de acero inoxidable pulido como espejo.

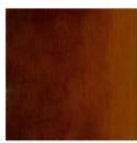

Láminas de Acero cotén.

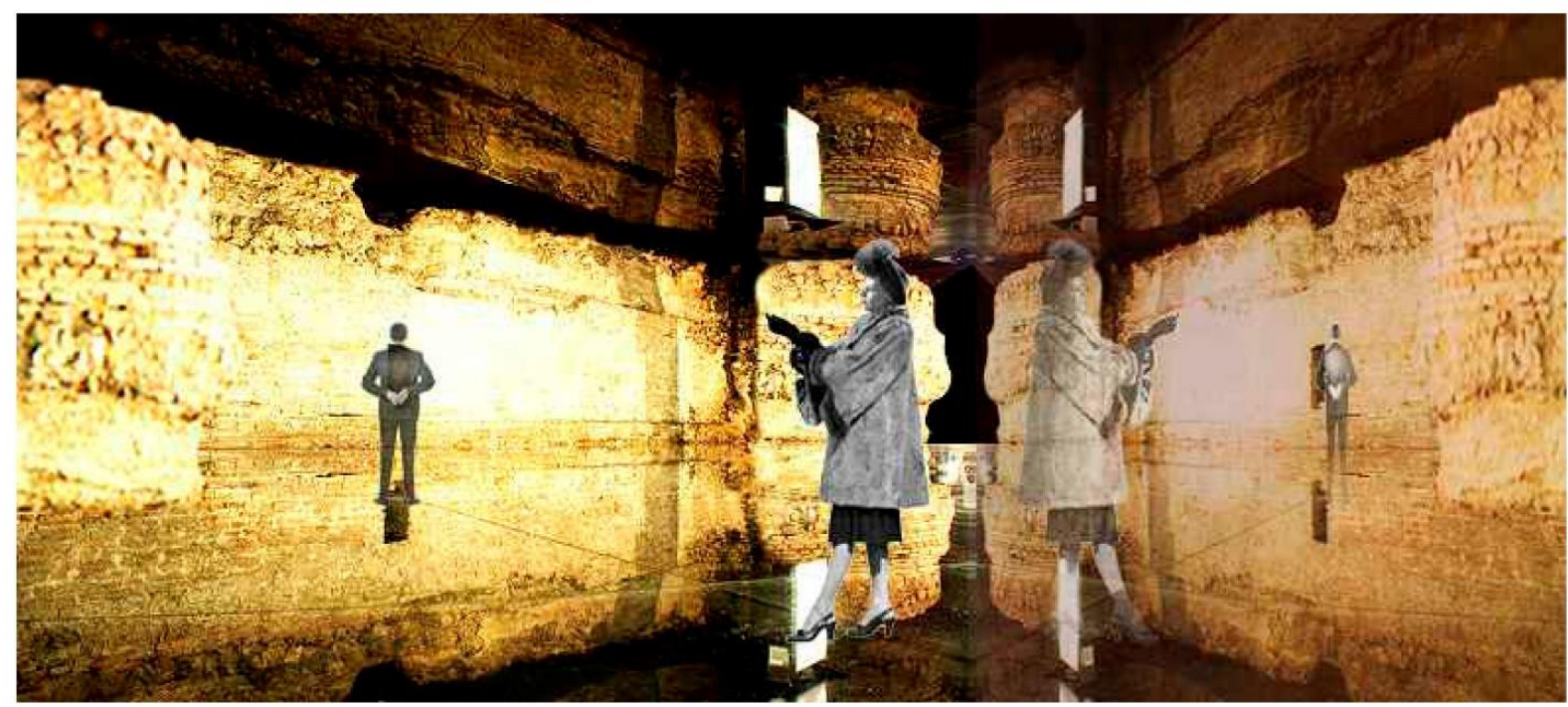

Fig. 9. Intervención en el espacio cultural del aparcamiento de la Plaza de la Marina, Málaga. Se interpretan las trazas históricas de cada época sobre el aparcamiento donde su ubican los restos arqueológicos. (Alumna: España, P.)

Advances in Building Education / Innovación Educativa en Edificación | ISSN: 2530-7940 |

http://polired.upm.es/index.php/abe

| Cod. 0003 | Mayo - Agosto 2018 | Vol. 2. № 2 | pp. 9/31 | 
Ciudades de Lectores: Innovación docente a través de una metodología que incorpora los espacios del lector en la literatura contemporánea para la iniciación al proyecto arquitectónico

Francisco Javier Castellano Pulido, Tomás García Píriz, Ana Gallego Cuiñas, Gracia Morales Ortiz
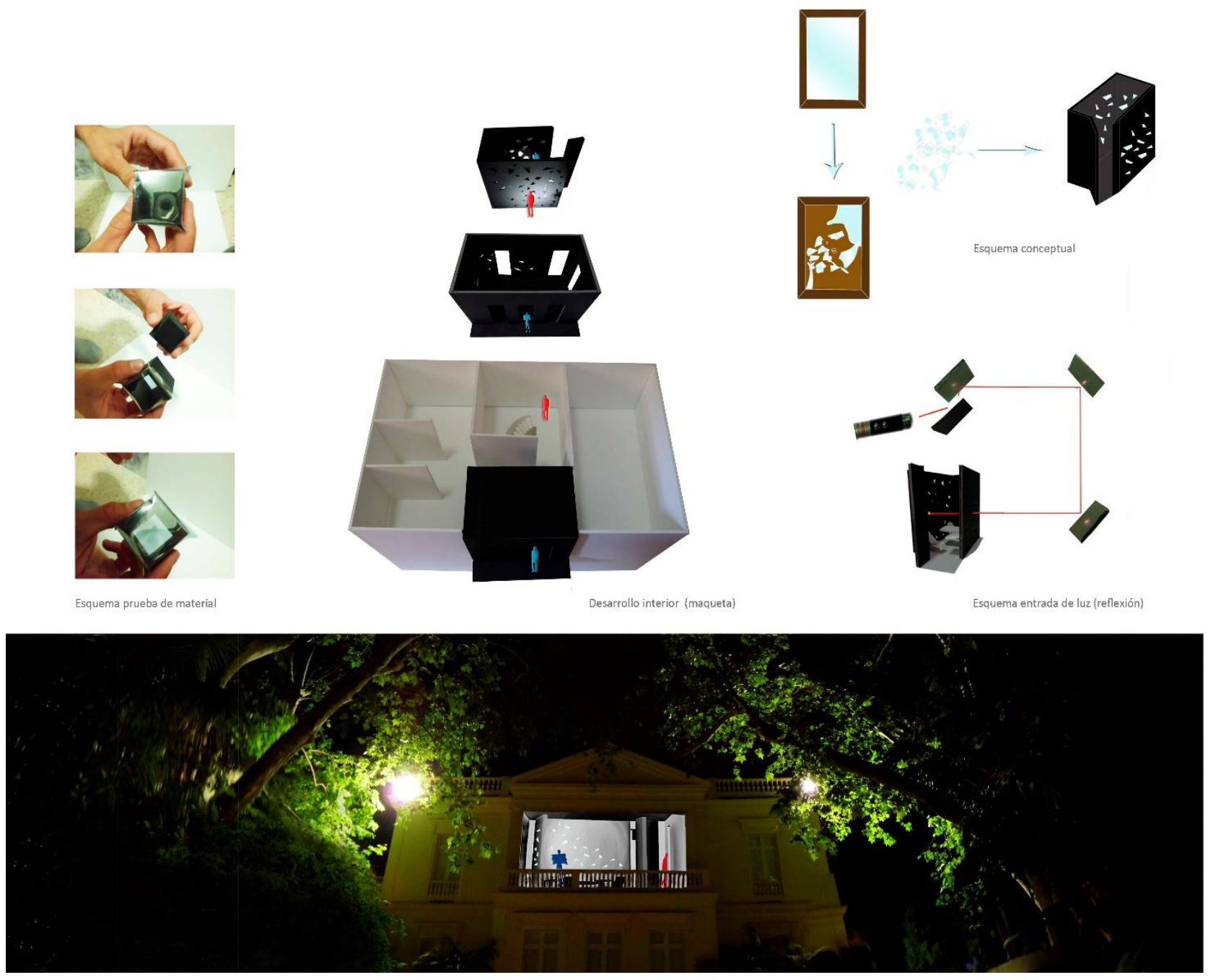

Fig. 10. Propuesta en la casa-palacio del jardín botánico La Concepción, Málaga. (Alumno: Muñoz, FJ.)

\subsubsection{Creación de blogs de cooperación interdisciplinar e interuniversitaria}

Como primera herramienta de intercambio de información, se creó el blog "Granada: ciudad de lectores" donde participaron todos los alumnos y comentaron sus impresiones. Este blog también fue la primera plataforma de exposición de los trabajos en grupo y permitió trabajar con las TICs en el aula, superando algunas de las limitaciones de las plataformas de docencia de cada universidad, abriendo al público el marco de actuación del proyecto de innovación docente y facilitando al alumnado la exposición o discusión de los trabajos [8]. Igualmente, se fomentó el diálogo interdisciplinar entre los alumnos de literatura y arquitectura, así como el contacto entre universidades. Se incluyó también una sección de explicación del blog, de etiquetado de lectores, citas y frases célebres relacionadas con la lectura, recomendando páginas web sobre fomento de la lectura y un relato creado para el blog de la escritora Pepa Merlo.

La dirección del blog es: http://granadaciudaddelectores.blogspot.com.e s/ 

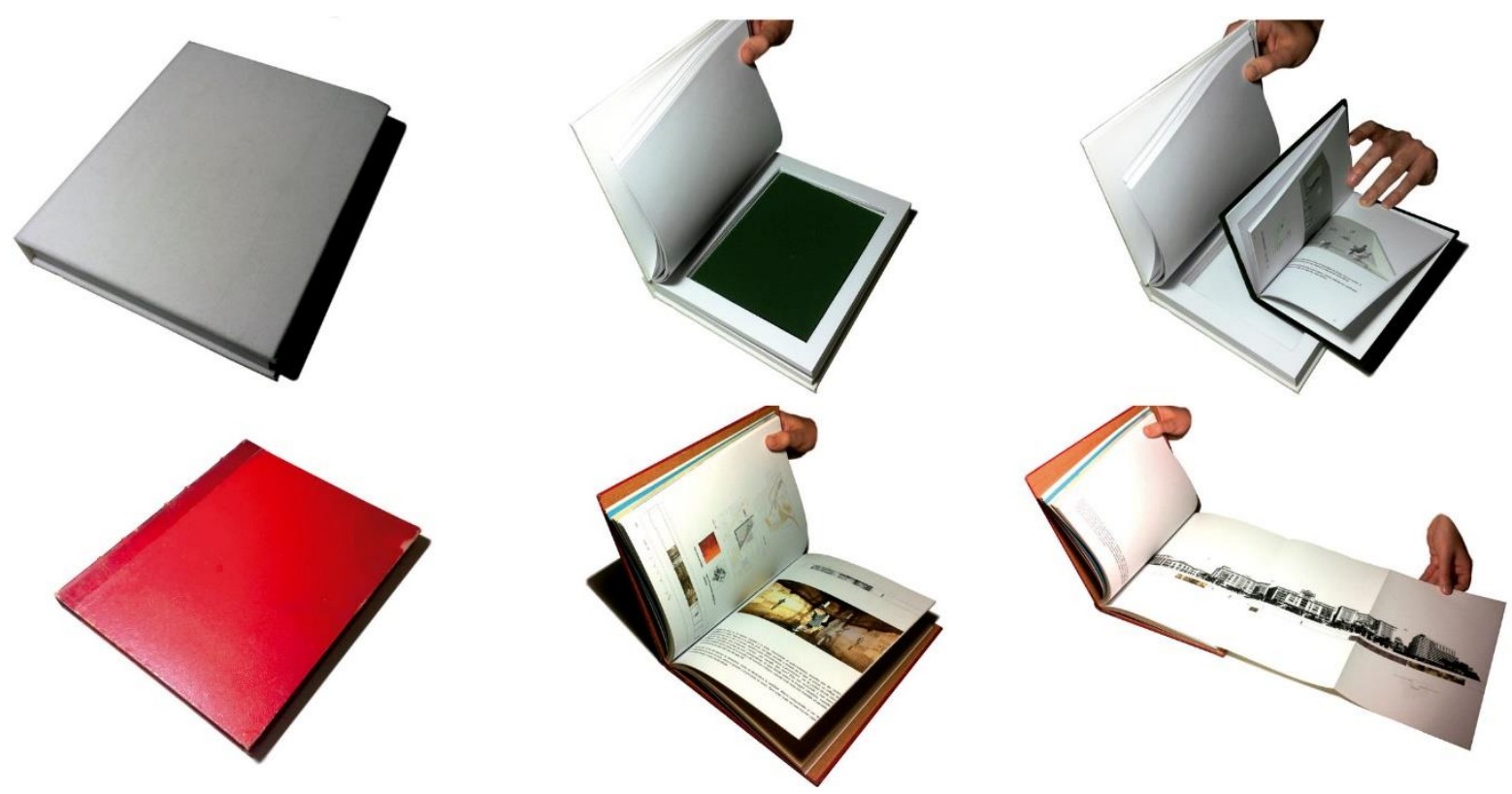

Fig. 11. Ejemplo de maque-libros con una mayor complejidad conceptual: meta-relatos (arriba) y capas del tiempo y de la memoria (abajo). (Alumnas: Mendoza; España, P.)

\subsubsection{La fábrica de maque-libros}

El esquema de intercambio de información e interpretación hasta la producción del proyecto puede verse en la denominada "fábrica de maque-libros", cuya denominación hace referencia a la página web interactiva llamada Ciudad de lectores, donde puede seguirse el proceso de desarrollo del trabajo. Este dispositivo de acceso público funciona como una "fábrica" donde puede seguirse paso a paso la transformación de los textos literarios en proyectos de arquitectura, incluyendo en cada momento los enunciados y los documentos entregados a los alumnos.

Se seleccionaron finalmente los mejores resultados obtenidos en las clases de literatura y arquitectura, así como los más destacados materiales recabados por el alumnado de las diferentes asignaturas y titulaciones de Filología Hispánica y Arquitectura (figura 11).
Véase la dirección de la web (figura 12):

\section{http://www.ugr.es/ ciudaddelectores/}

\subsection{Método teórico de intercambio}

Con el objeto de garantizar una cierta calidad en el intercambio de información entre disciplinas y estimular el pensamiento crítico, se dotó a los alumnos de literatura de conocimientos básicos sobre arquitectura respecto al espacio del lector y las cualidades espaciales. Del mismo modo, se realizó una exposición histórica y teórica a los alumnos de arquitectura sobre la función del libro, la lectura y los lectores en la ficción.

La clase magistral "El espacio del lector", fue llevada a cabo por los profesores de arquitectura en la Facultad de Filosofía y Letras de la Universidad de Granada, dando a conocer las representaciones artísticas de la lectura (la figura del lector en el cine, pintura, escultura, 
Ciudades de Lectores: Innovación docente a través de una metodología que incorpora los espacios del lector en la literatura contemporánea para la iniciación al proyecto arquitectónico

Francisco Javier Castellano Pulido, Tomás García Píriz, Ana Gallego Cuiñas, Gracia Morales Ortiz

fotografía), y analizando los factores ambientales y geográficos que podían influir en el ejercicio de la lectura en el espacio urbano.

La clase magistral "La lectura en el espacio; el espacio de la lectura" fue llevada a cabo por las profesoras de literatura en la E.T.S. de arquitectura de la Universidad de Granada y de la Universidad de Málaga. Esta lección permitió conocer las representaciones del lector en la ficción, los modos de lectura o los usos y apropiaciones del texto en la historia de la literatura.

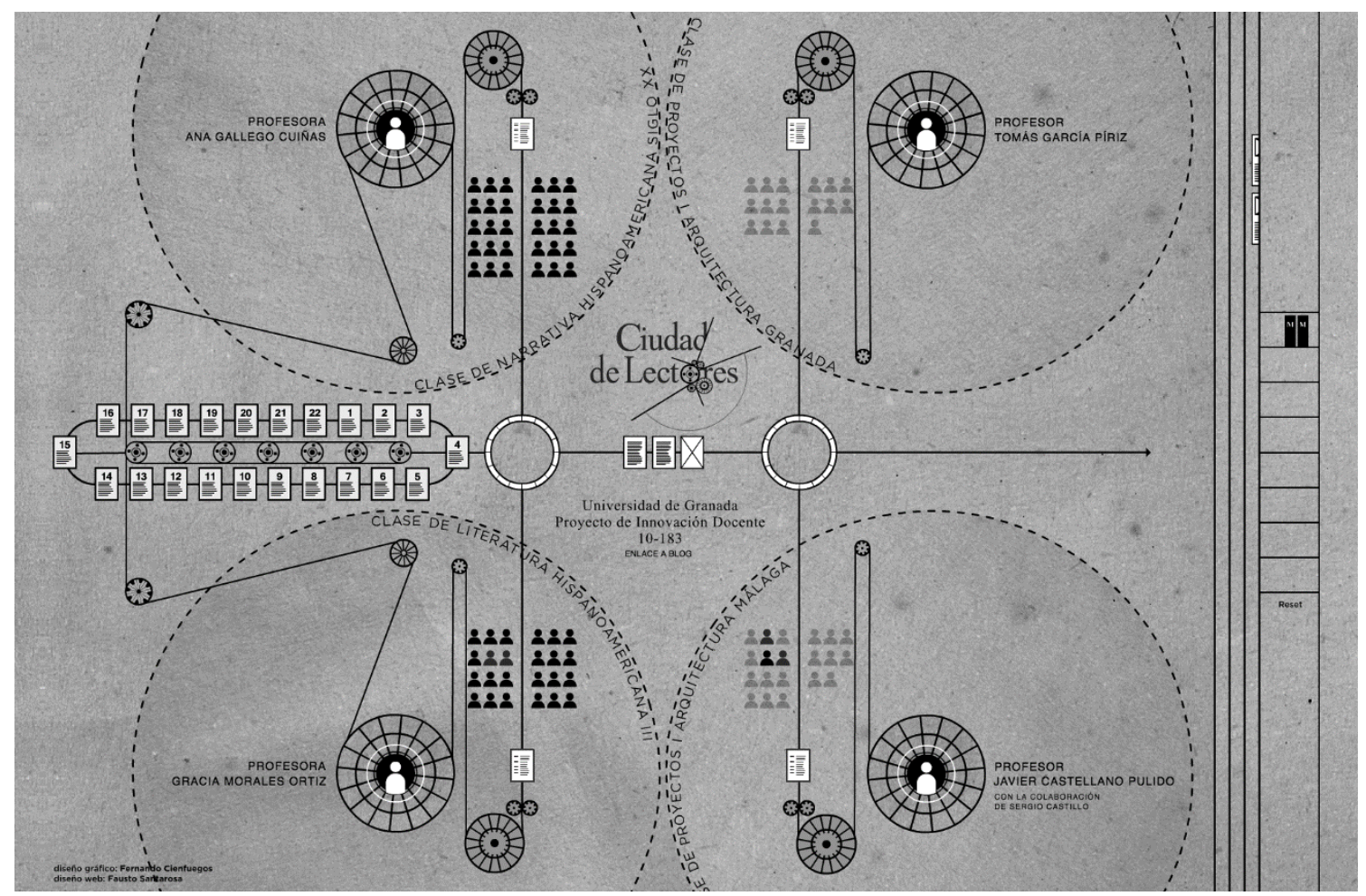

Fig. 12. Fábrica de maque-libros. Página web interactiva del proceso de aprendizaje por intercambio de información entre alumnos de Literatura y Arquitectura: http://www.ugr.es/ ciudaddelectores/

\section{RESULTADOS Y DISCUSIÓN}

\subsection{Resultados obtenidos}

La evaluación específica de la puesta en práctica del Proyecto de Innovación Docente se ha realizado a través de encuestas semiestructuradas anónimas al alumnado de literatura y arquitectura participante, procesando los datos y elaborando un informe final. Estas encuestas versaban sobre grado de satisfacción personal (fortalezas y debilidades del proyecto), la evaluación del profesorado (el responsable de cada asignatura y los invitados a dar una conferencia) y en general por la estructura y programación de tareas (figura 13).

Una vez examinado el resultado de las encuestas realizadas entre el alumnado de literatura, podemos observar que aproximadamente el $98 \%$ de los encuestados no habían participado anteriormente en un proyecto semejante. El trabajo ha supuesto variaciones en la metodología tradicional pero esta apreciación 
Ciudades de Lectores: Innovación docente a través de una metodología que incorpora los espacios del lector en la literatura contemporánea para la iniciación al proyecto arquitectónico

Francisco Javier Castellano Pulido, Tomás García Píriz, Ana Gallego Cuiñas, Gracia Morales Ortiz

no ha estado reñida ni con el interés suscitado ni con la eficacia alcanzada. Es decir, a pesar de que esta metodología manifiesta bastantes cambios respecto al método tradicional, ha resultado eficaz e interesante para los alumnos. De hecho, muchos de ellos recomendarían la iniciativa e implicarían a otras asignaturas como "Dibujo" o "Construcción".

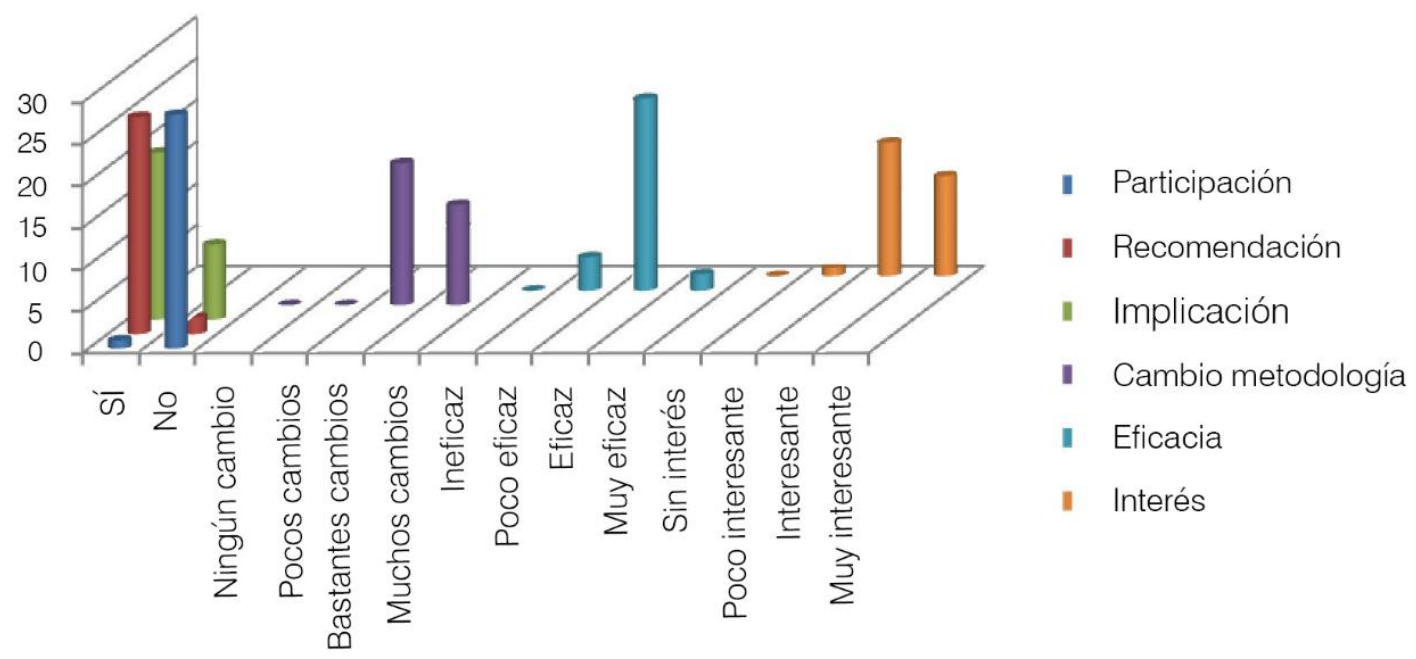

Fig. 13. Valoración de la metodología docente por parte de los alumnos de arquitectura

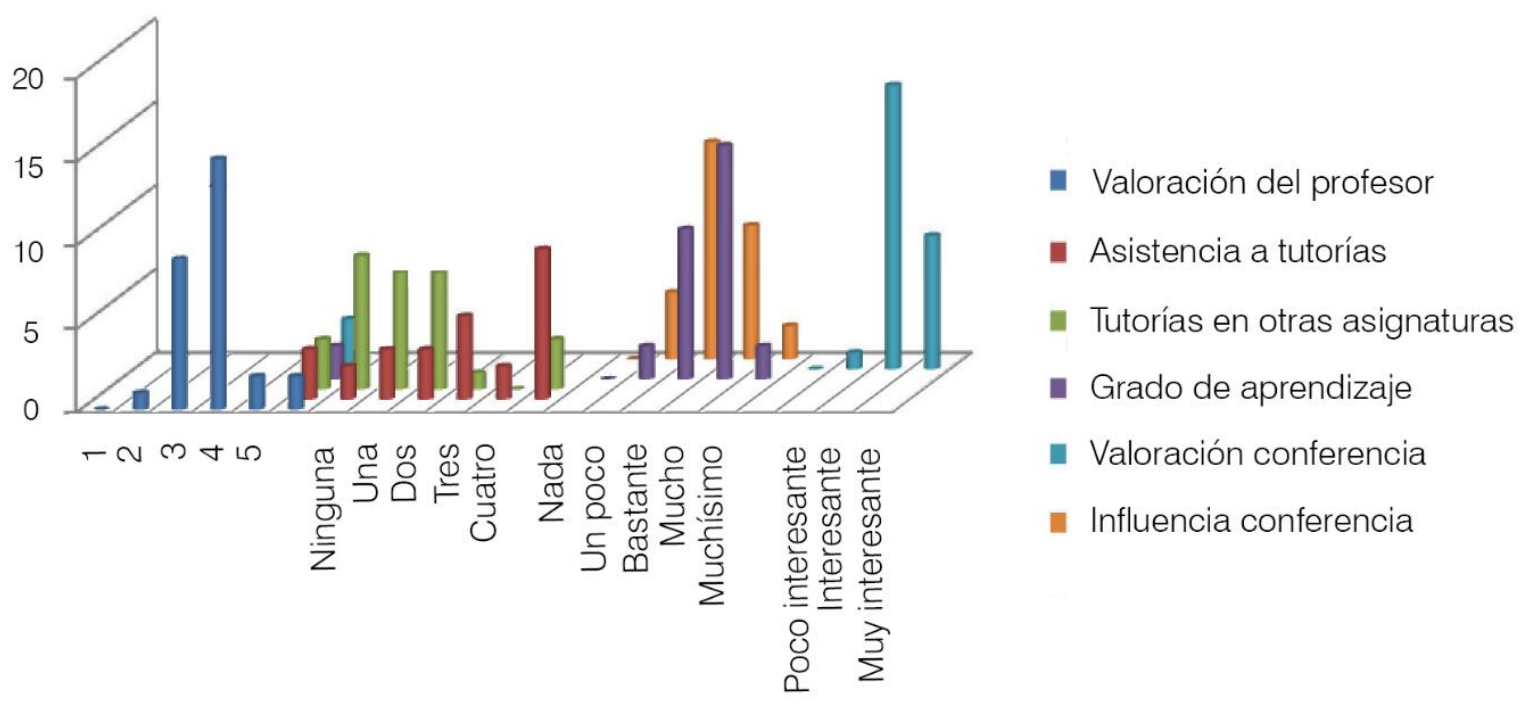

Fig. 14. Valoración de los profesores de Proyectos Arquitectónicos 1 por parte de los alumnos 


\section{Ciudades de Lectores: Innovación docente a través de una metodología que incorpora los espacios del lector en la literatura contemporánea para la iniciación al proyecto arquitectónico Francisco Javier Castellano Pulido, Tomás García Píriz, Ana Gallego Cuiñas, Gracia Morales Ortiz}

La evaluación de los profesores de Arquitectura por parte del alumnado es muy positiva (figura 14). De los 29 alumnos que tomamos como muestra, 26 dan de nota numérica entre 3 y 5 puntos, es decir, puntúan con una alta calificación a sus tutores. La asistencia a tutorías es dispar, aunque los gráficos dan a entender que quienes asisten en otras asignaturas, también lo han hecho para consultar dudas referentes al proyecto, lo que no supone ningún cambio apreciable, ni muestra que los alumnos hayan divagado por falta de conocimientos, materiales o explicaciones del profesor. Todo proyecto de cultura lleva implícito en primera instancia y como objetivo, que los integrantes logren aprender. Observando los gráficos [figs. 12 a 14], podemos afirmar que los índices confirman que el grado de aprendizaje obtenido alcanza cualquier expectativa calculada. Por otra parte, la conferencia "La lectura en el espacio-el espacio de la lectura", realizada por las profesoras de literatura a la que los alumnos de Arquitectura, según los datos de las encuestas, les resultó interesante y muy provechosa para la comprensión y ejecución del trabajo.

La evaluación del profesorado de Literatura (Filología Hispánica), por otra parte, alcanza la media de "excelente". La mayoría de los alumnos han consultado dudas unas 2 veces (media por alumno), sin embargo, este alumnado señala que no asiste a las tutorías de otras asignaturas. Las dudas surgidas durante la ejecución del proyecto, han sido consultadas a los profesores o compañeros del proyecto. Una minoría, en este caso, relevante, además le ha inquirido sobre sus vacilaciones a compañeros de otros cursos y a profesores de otras asignaturas. Asimismo, el alumnado manifiesta que le ha resultado interesante la conferencia, "El espacio del lector" pronunciada por los profesores de Arquitectura; y que le ha ayudado bastante en la elaboración del trabajo. También declaran que el espacio urbano en el que se ubica el lector, ayuda a la comprensión de la función de la lectura.

Finalmente, los estudiantes de literatura señalan como una dificultad el desconocimiento del tipo de lector que se representa en el texto y la complicación añadida que supone la elaboración de un trabajo creativo. El inconveniente más reiterado en las clases de Literatura y Arquitectura ha sido la demanda de más tiempo para su desarrollo. El tiempo invertido en el trabajo del proyecto (más de 40 horas según muchos de los encuestados) ha sido superior al invertido en otras asignaturas.

\footnotetext{
- Dificultad de comprensión de los textos de ficción escogidos

- Dificultad en el desarrollo del trabajo en equipo

- Dificultad en el desarrollo del trabajo individual

- Dificultad para trabajar en equipo
}

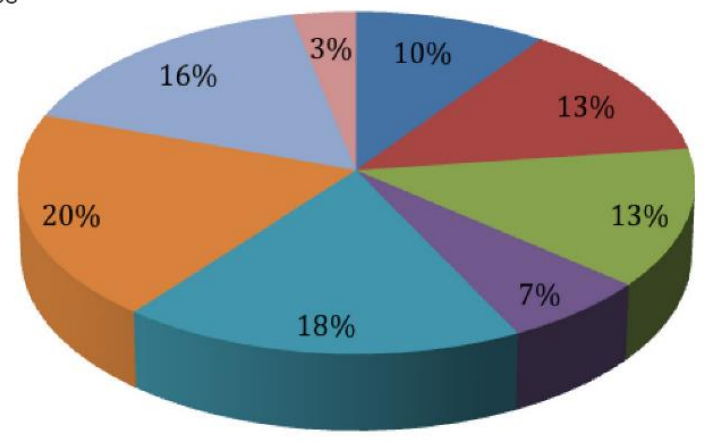

- Dificultad en el desarrollo de una actitud crítica apoyada en argumentos

- Dificultad en la ejecución de un trabajo creativo

- Dificultad en la traslación a la realidad de los espacios del lector en los textos

Otro tipo de dificultades no contempladas en la encuesta

Fig. 15. Dificultades detectadas en el desarrollo de la asignatura 


\section{Ciudades de Lectores: Innovación docente a través de una metodología que incorpora los espacios del lector en la literatura contemporánea para la iniciación al proyecto arquitectónico Francisco Javier Castellano Pulido, Tomás García Píriz, Ana Gallego Cuiñas, Gracia Morales Ortiz}

Comparando los datos obtenidos de las respuestas de los estudiantes de Arquitectura con las del alumnado de Literatura es posible ver cómo, si en los primeros la falta de guión o manual se señalaba como una dificultad, entre los últimos, la libertad metodológica es un acicate para la elaboración del proyecto.

También observamos que a casi todos los alumnos les ha surgido alguna dificultad respecto a la nómina enumerada anteriormente, pero sorprendentemente, un $20 \%$ ha tenido problemas a la hora de realizar un trabajo un creativo, cuando a la misma vez, apuntan que la mayor ventaja del proyecto es la libre interpretación (respaldada en argumentos que se sostienen textualmente) y la innovación que supone en su proceso de aprendizaje (figura 15).

\subsection{Productos generados}

Los vasos comunicantes que hemos establecido entre literatura y arquitectura han dado sus frutos en los trabajos críticos y creativos de los alumnos (véase este tipo de intercambios a través de los lugares imaginarios de Alberto Manguel, 2004 [10] y los pasadizos de Vicente L. Mora, 2007 [11]). Los blogs principales (para las clases de literatura y arquitectura granadaciudaddelectores.blogspot.com.es/ y el blog secundario para las clases de lengua:

\section{http://lectorcorrector.blogspot.com.es}

constituyen herramientas docentes que propiciaron la cooperación entre disciplinas. Al hacerlo público, contribuimos a la difusión del proyecto como producto digital relacionado con entornos reales [9]. Los resultados pueden verse en la web del proyecto donde se encuentran los mejores trabajos de los alumnos de literatura y arquitectura:

\section{http://www.ugr.es/ ciudaddelectores/}

Si los alumnos de Filología Hispánica "salieron del aula" para mirar la ciudad, escoger espacios y producir trabajos creativos (imagen fotográfica, video o composición musical), acercándose a ciertos conceptos que ayudan al intercambio de información entre disciplinas analíticas y prospectivas los alumnos de Arquitectura tuvieron que leer y aprender la función de la lectura en el texto para diseñar sus Proyectos Arquitectónicos, realizando maquelibros cuyo resultado también puede apreciarse en la web. Este intercambio de conocimiento y de herramientas colaborativas permitieron ampliar la dimensión perceptible del paisaje urbano de los alumnos (véase Ana Ma Moya, 2011 [12]), así como una mejora de la compresión de los lugares intermedios entre el espacio privado y el espacio público (véase Michele Petit, 2001 [13]).

\section{CONCLUSIONES}

La experiencia docente aquí presentada permite superar algunos de los principales prejuicios sobre la construcción del hábitat urbano y sus formas de cualificación espacial a partir de la comprensión de las múltiples formas contemporáneas de lectura. La definición de tipologías de lectores y lugares propicios para leer en dos ciudades distintas, la descripción de las condiciones espaciales para la práctica de la lectura y la exploración de la lectura como metáfora espacial permiten desarrollar una metodología docente innovadora en asignaturas de Filología Hispánica y Arquitectura. Esta metodología permite priorizar la reflexión crítica y el trabajo creativo, el aprendizaje interdisciplinario y la transferencia de conocimientos del aula universitaria a la ciudad.

La inclusión del espacio simbólico de la lectura en el programa arquitectónico, por otra parte, facilita la superación de los prejuicios de los 


\section{Ciudades de Lectores: Innovación docente a través de una metodología que incorpora los espacios del lector en la literatura contemporánea para la iniciación al proyecto arquitectónico Francisco Javier Castellano Pulido, Tomás García Píriz, Ana Gallego Cuiñas, Gracia Morales Ortiz}

alumnos de Proyectos Arquitectónicos de primer curso. Complementar las condiciones básicas de habitabilidad a las que suele responder el trabajo del arquitecto con otro tipo de "necesidades" de orden socio-cultural más complejo permite mejorar la capacidad de los alumnos para abordar cuestiones de índole antropológica que son fundamentales en la comprensión de la arquitectura y, sobre todo, en la construcción de la ciudad.

Las actividades docentes de intercambio entre realizadas en este proyecto entre la titulación y los nuevos Grados en Filología Hispánica y Arquitectura permitieron ampliar la visión de la relación entre la realidad imaginada y la realidad física. Esta labor se cristalizó en el intercambio de conceptos entre disciplinas que sirvieron de palabras clave para la "traducción" ficción literaria-espacio arquitectónico.

Los alumnos en las clases de literatura aprendieron a detectar e interpretar la experiencia lectora en función de variables espaciales que trasladaron de forma eficiente al contexto urbano en el que estaban inmersos, cuestiones que históricamente han sido orilladas o no tenidas suficientemente en cuenta por la crítica literaria, la arquitectura y las políticas culturales. El estudio del espacio del lector a partir de los análisis de condiciones urbanísticas, geográficas y ambientales del espacio público facilita también la utilización del proyecto arquitectónico como herramienta prospectiva para encontrar nuevas formas de inducir a la lectura. Como consecuencia, el alumno de Proyectos Arquitectónicos amplía de forma constatable su concepto de espacio y construye una lectura más rica sobre la realidad que observa, una lectura personal y proyectada hacia las múltiples potencialidades del espacio urbano de la actualidad.
Según los datos obtenidos mediante los resultados de las encuestas, se llega a la conclusión de que la mayor parte del alumnado participante en este Proyecto de Innovación docente queda satisfecho con su aportación personal con el tutelado por parte de los docentes y con el trabajo realizado. Por otra parte, al igual que todo requerimiento intelectual, ciertos aspectos del proyecto, pueden resultar complicados. Se detectan, por ejemplo, algunas carencias en el tiempo disponible o en la información previa: dificultad de comprensión de los textos escogidos, dificultad en el desarrollo del trabajo en equipo, en el desarrollo del trabajo individual y de una actitud crítica basada en argumentos, en la ejecución de un trabajo creativo, en la traslación sobre el espacio del lector y el acto de la lectura representado en los textos.

Este nuevo método de aprendizaje posibilita la puesta en práctica de ideas propias, acercándose a la teoría a través de los textos, y no viceversa, y eso es lo que han reflejado los alumnos en las encuestas.

Los blogs de intercambio de información literatura-arquitectura diseñados para el proyecto han servido de instrumento de enseñanza y aprendizaje en el aula, así como un modo eficaz de difusión de los trabajos críticos y creativos de los alumnos. El diseño de la web interactiva, por otra parte, revela el proceso y los resultados del proyecto, como una de esas máquinas fantásticas del siglo XIX cuyo engranaje ilustra su complejo funcionamiento. La construcción de su esqueleto es compleja, una suerte de arquitectura industrial capaz de dar soporte a la producción de cultura literaria y arquitectónica, que utiliza el combustible ficcional para ponerse en marcha: una máquina mágica de lecturas y lectores en la ciudad. 
Ciudades de Lectores: Innovación docente a través de una metodología que incorpora los espacios del lector en la literatura contemporánea para la iniciación al proyecto arquitectónico Francisco Javier Castellano Pulido, Tomás García Píriz, Ana Gallego Cuiñas, Gracia Morales Ortiz

\section{AGRADECIMIENTOS}

Este trabajo ha sido parcialmente subvencionado a través del Proyecto de Innovación Docente PID 10-183 de la Universidad de Granada: Granada: Ciudad de Lectores (Innovación en metodologías docentes para clases prácticas de literatura, lengua y arquitectura), con la participación de alumnos de Literatura Española, Lengua y Arquitectura de las Universidades de Granada y Málaga. Queremos agradecer a los profesores Álvaro Salvador Jofre (Literatura Española de la UGR), Gonzalo Águila Escobar (Lengua Española de la UGR) y Sergio Castillo Hispán (Proyectos Arquitectónicos 1 de la ETSA de Málaga), su colaboración en esta experiencia. Una mención especial precisa el trabajo del diseñador gráfico Fernado Álvarez de Cienfuegos y del alumno Fausto Santarosa, fundamental para la elaboración de la compleja página web interactiva.

\section{REFERENCES}

[1] Prieto JM. Aprendiendo a ser arquitectos: Creación y desarrollo de la Escuela de Arquitectura de Madrid (1844-1914). Madrid: Consejo Superior de Investigaciones Científicas, 2004, pp. 166-167.

[2] Catelli N. Testimonios tangibles. Barcelona: Anagrama, 2001, pp. 38-39

[3] Chartier R. Libros, lecturas y lectores en la Edad Moderna. Madrid: Alianza, 1993.

[4] Perec S. La vida: Instrucciones de uso. Madrid: Anagrama,1.992.

[5] Rykwert J. La idea de la ciudad: antropología de la forma urbana en el mundo antiguo. Madrid: Hermann Blume, 1985.
[6] Elíasson $O$ et al. Your house. New York: Library Council of the Museum of Modern Art, 2006.

[7] Revuelta F, Pérez L. Interactividad en los entornos de formación on- line. Barcelona: UOC, 2009.

[8] Castells M. La galaxia Internet: reflexiones sobre Internet, empresa y sociedad. Barcelona: Plaza y Janes, 2001

[9] Tapscott D. Creciendo en un entorno digital: la generación net. Santafé de Bogota: McGrawHill, 1998.

[10] Manguel A. Breve guía de lugares imaginarios. Madrid: Alianza, 2004.

[11] Mora V.L. Pasadizos. Espacios simbólicos entre arte y literatura. Madrid: Páginas de Espuma, 2007.

[12] Moya, A. M. La percepción del paisaje urbano. Madrid: Biblioteca Nueva, 2011.

[13] Petit M. Lecturas: del espacio íntimo al espacio público. México: Fondo de Cultura Económica, 2001. 